\title{
LOS EFECTOS DE LA MEDIA PRESCRIPCIÓN PENAL
}

\author{
THE HALF CRIMINAL STATUTES OF LIMITATION EFFECTS
}

FRANCISCO PARRA NÚÑEZ*

\section{RESUMEN}

Este trabajo propone una interpretación de los efectos de la media prescripción, con énfasis en que el criterio rector de la rebaja que mandata el art. 103 del Código Penal debe ser la menor o mayor proximidad entre el momento de la interrupción de la prescripción y el saldo faltante para completarla. Lo anterior, en virtud de una interpretación desde el telos de la llamada "media prescripción", fuertemente arraigada a la prescripción penal total.

Palabras Clave: Derecho penal; Código Penal Chileno; Media prescripción penal; Prescripción gradual; Determinación de la pena; Atenuantes muy calificadas.

\section{ABSTRACT}

This paper proposes an interpretation of the half criminal statutes of limitation effects, with emphasis on that the ruling standard of the reduction mandated by art. 103 of the Criminal Code, must be the least or greatest proximity

\footnotetext{
${ }^{*}$ Profesor de Derecho Penal de la Universidad de Talca. Abogado. Doctorando en Derecho, cohorte 2017, Universidad de Talca. Magíster en Derecho Penal por la Universidad de Talca y Universitat Pompeu Fabra. Licenciado en Ciencias jurídicas y Sociales por la Universidad de Concepción. Correo electrónico: fparra@minpublico.cl.

Agradezco la encomiable colaboración del Dr. Osvaldo Artaza Varela en la corrección de este artículo. Del mismo modo, reconozco y agradezco las acertadas observaciones del arbitraje al que se sometió esta publicación.

Trabajo recibido el 16 de enero de 2019, y aprobado para su publicación el 9 de diciembre de 2019.
} 
between the moment of the interruption of the criminal statutes of limitation and what is missing to complete it. The above, because of an interpretation from the telos of the so-called "half criminal statutes of limitation", strongly rooted in the total criminal statutes of limitation.

Keywords: Criminal law; Chilean Penal Code; Half criminal statutes of limitation; Gradual statutes of limitation; Penalty determination; Very qualified mitigators.

\section{INTRODUCCIÓN}

La llamada "media prescripción"l es una sub institución que se encuentra recogida en el art. 103 del Código Penal -en adelante, CP-. Opera en el evento de que hubiese transcurrido la mitad o más del tiempo previsto por la ley para extinguir la acción penal o la pena $-\mathrm{y}$ sin que se hubiere completado la totalidad del cómputo-, en cuya virtud, al momento de juzgarse al delincuente, se le debe aplicar la pena considerando al hecho desprovisto de agravantes y premunido de, a lo menos, dos minorantes muy calificadas.

En nuestro país, la media prescripción penal ha adquirido un importante lugar dentro del debate jurisprudencial asentado ante la Corte Suprema, en orden a determinar si ella resulta o no procedente respecto de los crímenes de lesa humanidad. ${ }^{2}$ Sin perjuicio de ello, lo cierto es que ni la jurisprudencia, como tampoco nuestra doctrina, han establecido criterios claros sobre cómo debe operar, en concreto, la rebaja de pena mandatada por el referido art. 103 CP. En este trabajo se propone, desde la perspectiva teleológica, que el contenido del referido artículo reconoce, en virtud de su historia y de los fundamentos de la media prescripción, un radio aplicativo que debe tener por criterio rector de la atenuación punitiva, la distancia temporal entre el

1 Denominada también como "prescripción gradual", como se indica en Garrido MontT, Mario, Derecho penal, parte general, Editorial Jurídica de Chile, Santiago, 2009, 4a ed. actualizada, p. 398; Cury UrzúA, Enrique, Derecho Penal, Parte General, Eds. Universidad Católica de Chile, Santiago, 2005, $7^{\text {a }}$ ed., p. 804.

2 Sobre este punto, véase PARRA NúÑEZ, Francisco, "La necesidad de la pena como criterio determinante en la procedencia de la regla del artículo 103 del Código Penal en ilícitos de lesa humanidad: Comentario a la sentencia 34.447-2016 de la Corte Suprema", Revista de Estudios de la Justicia, 2017, № 26, pp. 197-221. 
hecho y el momento de su condena, como también respecto del día en que el delincuente podría haber accedido a la eximente en su totalidad.

Para ello, se efectúa, primero, una exposición descriptiva del establecimiento del sistema prescriptivo nacional, para luego explicitar los antecedentes históricos directamente vinculados con la media prescripción. En un segundo acápite se efectúa un recorrido por los diversos fundamentos que se han atribuido a la disminución punitiva con el transcurso del tiempo, donde, acto seguido, se indican los que se creen adecuados para fundar la media prescripción en el sistema chileno. En un tercer capítulo se propone la determinación de los efectos de la media prescripción desde la premisa referida al inicio, esto es, que con el transcurso del tiempo la necesidad de pena va disminuyendo de forma gradual hasta desaparecer, para luego concluir que: i) la rebaja del art. $103 \mathrm{CP}$ en la imposición del castigo es obligatoria; ii) su quántum debe considerar la mayor o menor cercanía con el hecho punible y con el saldo restante para acceder a la prescripción total; iii) no opera tratándose de casos de prescripción intra processum, debido a que esta constelación es abarcada por la paralización reglada en el art. 96 $\mathrm{CP}$; iv) se encuentra totalmente ligada a la prescripción total, pues es una manifestación de la misma, lo que conlleva a aplicarle todas las restantes sub instituciones del sistema prescriptivo del mismo modo que a la eximente; y v) siempre que pueda ser procedente la prescripción total debe ser procedente también la media prescripción y, por el contrario, la negación de la primera inexorablemente impide acceder a la segunda.

\section{LA PRESCRIPCIÓN Y LA “MEDIA PRESCRIPCIÓN" EN EL ORDENAMIENTO CHILENO}

\section{El Sistema prescriptivo, en general.}

La génesis del sistema prescriptivo que consagra el CP de 1874 se encuentra en las actas de las sesiones de la Comisión Redactora del CP, en la especie, en cinco sesiones: la 21, de 27 de julio de 1870, donde se aprobaron los artículos que regulan la prescripción en el CP español de $1850 ;{ }^{3}$ la 138 , de 16 de mayo de 1873 , donde se establecen las bases sobre

3 Rivacoba Y Rivacoba, Manuel, Código penal de la República de Chile; y, Actas de las sesiones de la Comisión Redactora del Código Penal Chileno, EDEVAL, Valparaíso, 1974, pp. 290 y 291. 
las cuales se erige el sistema prescriptivo chileno; ${ }^{4}$ la 139 , de 19 de mayo de 1873, donde se consigna el texto legal que se pretendía fijar en el título V del CP, artículos 93 al $103 ;{ }^{5}$ la 140 , de 20 de mayo de 1873 , donde se discute y modifica el articulado prescriptivo, haciéndose refrendaciones y agregaciones que constituyen el texto definitivo del CP, excepto del artículo $102 ;{ }^{6} \mathrm{y}$, la 141 , de 21 de mayo de 1873 , donde se efectúan ajustes precisos al plazo de prescripción general y se agrega el artículo 102 al sistema. ${ }^{7}$

En la sesión 21 de la Comisión Redactora del Código Penal chileno simplemente se aprobó el articulado del título sexto del CP español de 1850, aceptándose el principio de la prescripción en materia criminal y agregándose que las faltas no obstaban a la eximente, aun si se hubieren cometido otras con anterioridad. ${ }^{8}$ En la sesión 138, el sr. FABres fue quien dispuso los lineamientos que serían considerados al momento de la configuración normativa del sistema prescriptivo: ${ }^{9}$

" $1^{\circ}$. que se distinga la prescripción de la pena i la de la acción penal; $2^{\circ}$ que para la primera se exija mayor tiempo que para la segunda, pues en ésta sólo existe de por medio el mandato de la lei, miéntras que en aquélla se agrega la resolución del juez que ha aplicado el precepto legal, i porque un delito no juzgado produce menor alarma que otro sentenciado i no castigado; $3^{\circ}$. que la prescripción de la acción penal se interrumpa por el juzgamiento del delito o por la ejecución de otro delito durante el tiempo de la prescripción; $4^{\circ}$. que una vez transcurrida la mitad del tiempo de la prescripción haya prescripción gradual, imponiéndose al culpable una pena menor que la que le

\footnotetext{
4 Yuseff Sotomayor, Gonzalo, La prescripción penal, Editorial Jurídica de Chile, Santiago, 2009, $3^{\mathrm{a}}$ ed., p. 31, sesión presidida por el sr. Reyes y con la asistencia de los señores Fabres, Gandarillas, Ibañez, Manuel Renjifo, y el secretario Osvaldo Renjifo.

5 Lazo, Santiago, Los Códigos Chilenos Anotados: Código Penal, orígenes, concordancias, jurisprudencia, Poblete Cruzat Hnos. editores, Santiago, 1915, p. 110, sesión presidida por el sr. Reyes y con la asistencia de los señores Altamirano, Gandarillas, Ibañez y Manuel Renjifo (secretario accidental).

${ }^{6}$ Rivacoba, cit. (n. 3), pp. 500, 501 y 502, sesión presidida por el sr. Reyes y con la asistencia de los señores Altamirano, Fabres, Gandarillas, Manuel Renjifo y el secretario Osvaldo Renjifo.

7 Rivacoba, cit. (n. 3), pp. 502 y 503, sesión presidida por el sr. Reyes y con la asistencia de los señores Altamirano, Fabres, Gandarillas, Ibañez, Manuel Renjifo y el secretario Osvaldo Renjifo.

8 Rivacoba, cit. (n. 3), p. 291.

9 Prieto, Ana, "Causales de extinción de la responsabilidad criminal; perdón del ofendido, prescripción de la acción penal y de la pena", Memoria de Prueba (pregrado), Facultad de Derecho Universidad de Chile, Editorial Universitaria, Santiago, 1955, p. 62. LAzo, cit. (n. 5), p. 110.
} 
correspondería en otro caso, i disminuyéndose aún más a medida que se acerque el término de la prescripción. $5^{\circ}$. que esta regla no se extiende a los fallos ni a las prescripciones especiales determinadas por este Código; $6^{\circ}$. que haya prescripción aunque el reo esté ausente de la República, doblándose el tiempo como en la prescripción civil; y $7^{\circ}$. que la prescripción corra contra toda clase de personas".

En la misma sesión, continúa el Acta, “el señor Gandarillas pidió que se tomasen como base las disposiciones reformadas del Código Español, que comprenden no solo la prescripción sino todos los modos como termina la responsabilidad criminal". Se ha entendido que la referencia al Código Español es al de $1850 .{ }^{10}$ Este cuerpo normativo, sin embargo, solo regulaba la prescripción de la pena ${ }^{11}$ y no la de la acción penal. ${ }^{12}$

Pues bien, de las bases propuestas por el Sr. Fabres se observó, a la signada en el numeral $6^{\circ}$, que no era conveniente aceptar la prescripción en el extranjero, ya que en ésta se produciría el efecto injusto de excluir fácticamente la posibilidad de aprehender al delincuente..$^{13}$ A la base contenida en el numeral $4^{\circ}$ se indicó que en la prescripción gradual resultaba conveniente conceder, en los casos en que hubiere transcurrido la mitad o más del plazo de prescripción, un efecto igual a aquel asignado a la concurrencia de dos o más atenuantes muy calificadas, permitiendo al juez rebajar la pena asignada por ley al delito hasta en tres grados, limitando esta regla a la prescripción que exceda de cinco años. ${ }^{14}$

Finalmente, la tarea de redactar los artículos que regularían la materia

\footnotetext{
${ }^{10}$ Así lo entiende Prieto, cit. (n. 9), p. 61.

${ }^{11}$ En los artículos 126 y 127 del Título Séptimo del Libro Primero, denominado "de la prescripción de las penas".

${ }^{12}$ En efecto, tanto el Código de 1848 como en las reformas de 1850 se mantienen idénticos estatutos normativos para la prescripción, prescindiendo de reglamentar la acción penal, como se consigna en PACHeCo, El código penal concordado y comentado, Tomo II, Imprenta de D. Santiago Saunaque, Madrid, 1848, pp. 542 y 543 (refiriéndose al CP de 1848), y en PACHECO, Joaquín, El código penal concordado y comentado, Segunda edición, corregida y aumentada, Tomo I, Imprenta de la viuda de Perinat y Compañía, Madrid, 1856, p. 528 (refiriéndose al CP tras las reformas de 1850), donde se transcribe el idéntico párrafo siguiente: “(...) No creemos nosotros que ni la Comision de Códigos ni el Gobierno hayan querido proscribir la doctrina de la prescripción de los delitos, por no haberla consignado en la ley que vamos recorriendo. Juzgamos que la han creido más propia del Código de actuacion, como que se reduce á una pérdida de acciones; y que por esa causa no la han incluido en el penal".

${ }^{13}$ Rivacoba, cit. (n. 3), p. 498.

${ }^{14}$ Lazo, cit. (n. 5), p. 110.
} 
fue encomendada al sr. Renjifo, considerando las bases propuestas por el sr. Fabres y la normativa del CP español de $1850 .{ }^{15}$ Así las cosas, en la sesión 139 el sr. Renjifo dio lectura al articulado del título V "De la extinción de la responsabilidad penal", examinándose cada precepto, los que fueron aprobados íntegramente, modificándose solo el inciso final del artículo 94, con el objeto de que se refiriera en términos generales a las prescripciones de corto tiempo, y se agregó el artículo 100, el cual regula la prescripción del reo que se ausenta del territorio de la república, aumentando al doble su plazo y fijando un máximum de 20 años en todo caso. ${ }^{16}$

De este modo, el sistema concebido por la comisión redactora estableció un estatuto normativo tanto para la prescripción de la acción penal como para la de la pena, y también disposiciones comunes a ambas. Los artículos que en definitiva regulan la materia van desde el 93 al $104 \mathrm{CP}$, ambos inclusive. El artículo $93 \mathrm{CP}$ establece los casos en que se extingue la responsabilidad penal, y en sus números 6 y 7 se refiere a la prescripción de la acción penal y de la pena, respectivamente. La prescripción de la acción pena $1{ }^{17}$ se reguló en los artículos $94 \mathrm{CP}$, que fija los diversos plazos según la gravedad de los delitos, $95 \mathrm{CP}$ que determina la manera de computar dichos plazos, y $96 \mathrm{CP}$, que contempla la interrupción y la suspensión de la prescripción (por la comisión de un nuevo delito, la primera, y por el direccionamiento del procedimiento contra el delincuente, la segunda). La prescripción de la pena se reguló en el artículo $97 \mathrm{CP}$, que fija los plazos, $98 \mathrm{CP}$, que señala cómo computarlos, y $99 \mathrm{CP}$, donde se contempla la interrupción de la prescripción de la pena. Las normas de aplicación general se encuentran en los artículos $100 \mathrm{CP}$, que regla la prescripción extraordinaria para quien se ausente del territorio de la república durante su

\footnotetext{
${ }^{15}$ Rivacoba, cit. (n. 3), p. 498.

16 Ídem.

${ }^{17}$ En Etcheberry, Alfredo, Derecho Penal, Parte General, Editorial Jurídica de Chile, Santiago, 1999, $3^{\text {a }}$ ed. revisada y actualizada, T. II, p. 257, en relación a la terminología empleada "prescripción de la acción penal", la cual reemplazó, en la regla del numeral $6^{\circ}$, a la versión originalmente propuesta por el sr. Renjifo "prescripción del delito", en la sesión 140, por estimarse que era más adecuada que aquella, comenta, en favor de esta decisión, que el delito es un acontecimiento que no puede ser borrado por el transcurso del tiempo, sino que lo que realmente se acaba o extingue es el derecho a perseguir su castigo, es decir, la acción penal. En CuRY, cit. (n. 1), p. 800, se formula una férrea defensa de la errónea denominación "prescripción de la acción penal" en desmedro de la de "prescripción del delito" del modo siguiente: "el término de la prescripción del delito (...) corre desde la comisión del hecho y si resulta que este hecho no trasciende, bien respecto de su producción, bien respecto de su significado antijurídico, es claro que se iniciará la prescripción pese a que la acción persecutoria no puede ser ejercida... Así, lo que realmente prescribe es el delito, cuyo disvalor decae, desgastado por la acción del tiempo".
} 
curso, $101 \mathrm{CP}$, donde se indica que corre contra toda persona (originalmente regulaba la media prescripción), ${ }^{18} 102 \mathrm{CP}$, que establece el deber de declararla de oficio (originalmente regulaba la prescripción de la reincidencia), $103 \mathrm{CP}$, relativo a la media prescripción (originalmente regulaba los efectos civiles del delito), 104, que contempla la prescripción de la reincidencia y $104 \mathrm{CP}$, que trata sobre los efectos civiles de la prescripción penal.

Así las cosas, entonces, los principales rasgos del régimen chileno en el ámbito prescriptivo son fundamentalmente los que siguen: i) existe una escala gradual en atención a la gravedad de los ilícitos, que determina el plazo en que éstos prescribirán, ${ }^{19}$ sin perjuicio de la improcedencia de la institución en los denominados crímenes de lesa humanidad, incorporados en nuestro ordenamiento como consecuencia del reconocimiento jurisprudencial de las normas que imponen esta restricción en el derecho internacional humanitario, sin perjuicio de su establecimiento posterior por la Ley $20.357,{ }^{20}$ como también respecto de ciertos delitos sexuales cometidos contra menores de edad; ${ }^{21}$ ii) tratándose del inicio del cómputo prescriptivo, éste se verifica cuando se hubiere cometido el delito, con las dificultades que ello presenta debido a una serie de constelaciones específicas que no han sido resueltas por el legislador nacional, ${ }^{22}$

${ }^{18}$ La expresión "originalmente" se utiliza para aludir a la primera propuesta del articulado del Título V presentada por el sr. Renjifo.

${ }^{19}$ A la regla general del art. $94 \mathrm{CP}$, donde se distinguen cuatro plazos diversos según la gravedad de las infracciones (crímenes perpetuos, crímenes, simples delitos y faltas), deben añadírseles las restantes prescripciones contempladas en otras disposiciones del $\mathrm{CP}$ y leyes especiales que establecen plazos diversos, como ocurre con el art. $431 \mathrm{CP}$ relativo a injurias y calumnias.

${ }^{20}$ Sobre este punto, véase nota ${ }^{\circ} 83$.

${ }^{21}$ De conformidad a lo previsto en la Ley 21.160, "Declara imprescriptibles los delitos sexuales cometidos contra menores de edad", promulgada el 11 de julio de 2019 y publicada el día 18 del referido mes, que inserta el nuevo art. 94 bis CP.

${ }^{22}$ Tales constelaciones son: (i) las formas imperfectas del iter crimen donde se ha entendido que el cómputo en la tentativa, debe iniciarse el día del último acto ejecutivo realizado, y en la frustración, desde el momento en que surge el obstáculo que impide la consumación. Así, RaGuÉs I VaLLÉs, Ramón, La prescripción Penal: fundamento y aplicación, Editorial Atelier, Barcelona, 2004, pp. 128-129; Wessels, Johannes, Derecho Penal, Parte General, Trad. de Finzi, Conrado, Depalma, Buenos Aires, 1980, 6 a ed. alemana, p. 173; Yuseff, cit. (n. 4), pp. 81-82; Politoff, Sergio; Matus, Jean Pierre; Ramírez, María, Lecciones de Derecho Penal chileno, Parte General, Editorial Jurídica de Chile, Santiago, 2004, $2^{\mathrm{a}}$ ed. actualizada, p. 584. Diversos ordenamientos resuelven positivamente el problema, como el art. $102 \mathrm{n}^{\circ} 2$ del CP Federal de México y art. 119 del CP del Uruguay; (ii) En la participación criminal, el término comenzaría a correr para todos los partícipes por igual, desde la ejecución del último acto delictivo; (iii) En lo relativo al delito continuado y al permanente, en algunos ordenamientos se resuelve el problema en forma expresa, como en el art. $132 \mathrm{n}^{\circ} 1$ del CP Español. En doctrina se ha estimado que en el delito continuado el término correría desde que se ejecuta la última de las infracciones. Así, Mezger, Edmund, Derecho Penal, Parte General, trad. de la $2^{\mathrm{a}}$ ed. alemana por Rodríguez, José, Editorial Revista de Derecho Privado, Madrid, 1957, T. II, p. 421. En este sentido, 
exceptuándose la injuria y la calumnia; ${ }^{23}$ iii) la interrupción se produce desde el momento en que el delincuente comete un nuevo crimen o simple delito: de inmediato comienza a correr otra vez el término, en paralelo con el correspondiente a la nueva infracción; ${ }^{24}$ iv) se suspende el cómputo desde que el procedimiento destinado a perseguir la responsabilidad penal por el delito de cuya prescripción se trata, se dirige contra el delincuente; se reanuda el cómputo desde que el procedimiento se paraliza por cualquier causa por tres años, o desde que termina sin ser condenado, como si no se hubiere suspendido; v) dos días de permanencia del delincuente fuera del territorio de la República durante el curso del plazo de prescripción, equivalen a uno dentro de ella, para el cómputo de los años; ${ }^{25}$ vi) si el culpable es habido o se presenta antes de cumplirse el tiempo total de prescripción, pero habiendo trascurrido la mitad o más del mismo, se debe considerar al hecho como revestido de dos atenuantes muy calificadas y ninguna agravante; ${ }^{26}$ vii) la prescripción debe ser declarada de oficio por el tribunal que conoce de la causa. ${ }^{27}$

sentencia del Tribunal de Juicio Oral en lo Penal de Talca, 18 de enero de 2013, rol n 214-2012, considerando $9^{\circ}$, que se refiere a la prescripción declarada respecto de uno de los delitos imputados, que había sido calificado como continuado, indicando que "forzoso es concluir que respecto de éste ilícito, ha transcurrido el aludido plazo de prescripción, que por disposición del artículo 95 del citado Código, empieza a correr desde el día en que se cometió el delito; en este caso, a lo menos, desde marzo de 2007 , considerando que resultó probado que las tocaciones cesaron en el verano de dicho año". En los delitos permanentes, el término comenzaría a correr desde que se verifica la terminación del ilícito. Así, Mañalich Raffo, Juan Pablo, Terror, pena y amnistía: el derecho penal ante el terrorismo de Estado, Flandes Indiano, Santiago, 2010, p. 166. Una terminología diversa, aunque con igual solución, en Welzel, Hans, Derecho Penal alemán, Trad. de Bustos, Juan y Yáñez, Sergio, Editorial Jurídica de Chile, Santiago, 1976, $2^{\text {a }}$ ed. castellana, p. 118, y en Stratenwerth, Günter, Derecho Penal, Parte General, Tomo I, El hecho punible, Trad. Canció Meliá, M. y Sancinetti, M., Editorial Aranzandi, Navarra, 2005, p 351. En MEzGER, cit. (n. 22) se señala que la prescripción comienza desde que cesa el estado antijurídico. En el mismo sentido, aunque con matices, PARRA NúÑEZ, Francisco, "Prescripción penal y delito permanente", Revista de la Facultad de Derecho (U. de la República, Uruguay), 2019, $\mathrm{N}^{\circ} 47$, p. 9 y ss., artículo disponible en línea: https://doi.org/10.22187/rfd2019n47a4 (fecha de visita: 12 de septiembre de 2019).

${ }^{23}$ Art. 431 CP.

${ }^{24} \mathrm{Al}$ decir de Guzmán Dalbora, José Luis, “Artículos 93 a 105, de la extinción de la responsabilidad penal”, en Politoff, S., Ortiz, L.(dirs.), Texto y comentario del Código Penal chileno, Editorial Jurídica de Chile, Santiago, 2002, T. I, pp. 460 y ss, p. 472, el término comienza a correr ex novo et ex integro.

${ }^{25}$ Ésta es la llamada prescripción extraordinaria, prevista en el art. $100 \mathrm{CP}$.

${ }^{26}$ Art. 103 CP.

${ }^{27}$ Art. 102 CP. 


\section{La configuración de la llamada "Media prescripción".}

Como se señaló al inicio de este trabajo, la llamada "media prescripción", ${ }^{28}$ prevista en el art. $103 \mathrm{CP}$, opera cuando hubiese transcurrido la mitad o más del tiempo exigido para la prescripción penal -y sin que se hubiere completado la totalidad del cómputo-, cuyo efecto es conferir al delincuente, en su juzgamiento, dos minorantes muy calificadas y eliminar toda agravante que pudiera concurrir.

Su origen se halla, como se dijo, en las actas de la Comisión Revisora del Código Penal chileno de 1874, donde el civilista Fabres propuso en la cuarta base del sistema -transcritas íntegramente supra-que:

“(...) una vez transcurrida la mitad del tiempo de la prescripción haya prescripción gradual, imponiéndose al culpable una pena menor que la que le correspondería en otro caso, i disminuyéndose aún más a medida que se acerque el término de la prescripción". 29

La idea del sr. Fabres era que se aplicara una pena menor de manera progresiva con el acercamiento del término de prescripción total. Sin embargo, la fórmula gradual no prosperó, sino que se optó por conceder la "media prescripción" al verificarse la mitad del tiempo total de ésta. ${ }^{30}$ En este orden de ideas, se propuso la consagración normativa de la directriz del sr. Fabres, cuya redacción fue hecha por el sr. Renjifo, en el art. $101^{31}$ del proyecto, al siguiente tenor:

“Art. 101: Si el reo se presentare o fuere habido ántes de completarse el tiempo de la prescripción de delito o pena, pero habiendo transcurrido ya la mitad del que se exije en sus respectivos casos para tales prescripciones, deberán los tribunales considerar el hecho como revestido de dos o más circunstancias atenuantes mui calificadas i de ninguna agravante, i aplicar las reglas de los arts. 65, 66, 67 i 68, sea en la imposición de la pena, sea para disminuir la ya impuesta.

Esta regla no se aplica a las prescripciones de cinco años o ménos”.

\footnotetext{
${ }^{28}$ Denominada también como "prescripción gradual", como se indica en nota al pie n. 1.

${ }^{29}$ RivacoBa, cit. (n. 3), p. 500.

${ }^{30}$ Por ello resultaría más adecuada la terminología que denomina a la institución del art. 103 CP como "media prescripción" y no aquella que la designa como "prescripción gradual".

${ }^{31}$ Quedó, definitivamente, en el art. 103, debido a los artículos incorporados en los números 101 y 102 en la sesión 140 de la comisión redactora, en RivacoBA, cit. (n. 3), p. 500.
} 
En el artículo definitivo se modificó el inciso final de la norma, ${ }^{32}$ excluyendo de la aplicación de la "media prescripción" a las faltas y las prescripciones especiales de corto tiempo. ${ }^{33}$ Posteriormente, se modificó la terminología referida al reo para adaptarla al lenguaje de la Reforma Procesal Penal. ${ }^{34}$

\section{LOS FUNDAMENTOS DE LA MEDIA PRESCRIPCIÓN}

\section{Los fundamentos de la media prescripción, en general.}

Consignado a modo de pregunta, la existencia de la "media prescripción" responde, ante todo, a la siguiente cuestión: aquellos hechos que han quedado muy cerca del momento de su prescripción, pero sin llegar a alcanzarlo ¿Merecen algún tipo de respuesta atenuada por parte del Derecho Penal? ${ }^{35}$ La respuesta en nuestro ordenamiento, según lo prescribe el art. $103 \mathrm{CP}$, resulta, en general, afirmativa.

En el plano dogmático, la justificación de una respuesta atenuada de la reacción penal antes de que se alcance la totalidad del plazo establecido legalmente para la prescripción total del delito, pero habiendo transcurrido un largo tiempo desde la perpetración del ilícito, viene dado por el hecho de que todo tipo de justificativo de la prescripción penal parece no producirse en un instante preciso, de un momento a otro, donde se pasa de una total necesidad de castigo a una total ausencia del mismo. Por el contrario, en todo caso, ${ }^{36}$ el tiempo produce sus efectos en la necesidad de punición de forma paulatina, poco a poco, día a día a contar del hecho delictivo. ${ }^{37}$

\footnotetext{
${ }^{32}$ Sesión 169, de 3 de octubre de 1873, RivacoBa, cit. (n. 3), p. 554.

${ }^{33}$ Pese a que no existen referencias históricas del motivo que llevó a la Comisión Redactora del CP de 1874 a tomar una decisión como ésta, parece razonable entender que en las prescripciones de corto tiempo más que considerar al hecho delictivo o al sujeto, se atiende a razones de índole adjetiva, donde la eximente funciona como una especie de mecanismo de selección de casos, completamente desconectada de sus fundamentos sustantivos, como se señala infra.

${ }^{34}$ Art. 1 de la Ley n 19.806, donde se sustituye la palabra "reo" por la de "responsable".

${ }^{35}$ En similares términos lo señala Ragués I Vallés, Ramón, "La atenuante analógica de cuasiprescripción”, InDret - Revista para el análisis del Derecho, 2017, N³, p. 2.

${ }^{36}$ Quizás con la sola excepción de los justificativos de la prescripción penal asilados en la "seguridad jurídica", no obstante que estimamos, por las razones señaladas supra, que dicha premisa no constituye un fundamento de la institución. En detalle sobre este punto, RAGUÉs, cit. (n. 35), p. 13.

${ }^{37}$ Así lo asume Welzel, cit. (n. 22), p. 359. También Jescheck, Hans H., Tratado de Derecho Penal,
} 
Sin perjuicio de lo señalado, existen otras instituciones penales que reconocerían en el transcurso del tiempo consecuencias jurídicas que afectan a los ciudadanos, como el establecimiento de la mayoría de edad como límite mínimo a partir de la cual rige la responsabilidad criminal propia de los adultos $-\mathrm{y}$ sin perjuicio del sistema especial de responsabilidad penal adolescente-, donde las reglas operan de manera radical, de un instante a otro. Al respecto, parece correcto afirmar que un criterio enraizado en la idea de imputabilidad, como falta de capacidad de conocer el injusto o falta de capacidad de actuar en consecuencia con el conocimiento del injusto, basado en la importación de razonamientos del orden de las ciencias naturales, particularmente aquellos que descansan en la psicología o en la psiquiatría, puede hallar asilo en que en los límites que el legislador fija para que un sujeto pueda ser acreedor de responsabilidad penal resultarían arbitrarios, al entender que quien tiene 17 años y 364 días de edad no será responsable, frente a quien ostenta 18 años recién cumplidos, quien sí será castigado como adulto. Sin embargo, en tales constelaciones los criterios que justifican una delimitación radical del tratamiento temporal aplicable encuentran correlato en el entendimiento de esta clase de responsabilidad desde una perspectiva valorativa, donde el problema de la imputabilidad gira en torno a la consideración del individuo como persona, esto es, como un sujeto dotado de derechos y al que se le pueden imponer obligaciones: esto es, de un sujeto dotado de autonomía, ${ }^{38}$ que, desde una consideración político jurídica, coincide con la edad establecida como mínima para la plena participación político social, esto es, 18 años de edad. Desde esta perspectiva, no se trata de que el adolescente de 17 años y 364 días de edad tenga una madurez menor a la de un sujeto de 18 años de edad recién cumplidos, sino que solo este último se encuentra en una posición de reconocimiento pleno de su participación político social y, por lo mismo, se puede imponer respecto de él una reacción penal, en dicha perspectiva, justificada. ${ }^{39}$

La prescripción, por el contrario, se ha justificado desde diversas perspectivas, tanto de índole procesal como sustantivas, que se suelen

Parte general, Editorial Comares, Granada, 1993, 4a ed, p. 822. En el mismo sentido se pronuncia Antón Oneca, José, Derecho Penal, Editorial Akal, Madrid,1986, 2a ed., p. 612.

${ }^{38}$ Bustos Ramírez, Juan, “Imputabilidad y edad penal”, en: Echeburúa, E.; de la Cuesta, J.; Dendaluce, I. (coords.), Criminología y derecho penal al servicio de la persona: libro homenaje al profesor Antonio Beristain, Ed. Instituto Vasco de Criminología, San Sebastián, 1989, pp. 471-482, p. 472.

${ }^{39}$ Para un análisis de la problemática en España, véase Bustos, cit. (n. 38), pp. 471-482 
denominar como "fundamentos de la prescripción penal", ${ }^{40}$ todas las cuales llevan implícitamente la idea de que no operan de un momento a otro, sino que lo hacen de forma paulatina. El gran número de fundamentos que se atribuyen a la eximente constataría que, en la determinación de los mismos influyen directamente las formulaciones normativas de cada ordenamiento; y precisamente es este caos de las regulaciones normativas -donde el ordenamiento nacional no hace excepción- el que ha devenido en irradiar tanto a la jurisprudencia como a la doctrina. ${ }^{41}$

Así las cosas, incluso se ha sostenido que el fundamento de la eximente se encontraría en consideraciones político criminales, donde su reconocimiento emanaría del siguiente razonamiento: si, transcurrido cierto tiempo, puede estimarse que el castigo implica mayores perjuicios que beneficios, debe accederse a la prescripción penal. Esta posición, sin embargo, lejos de explicar la razón de ser de la prescripción penal, solo permite constatar lo evidente: el por qué se establece la eximente. ${ }^{42}$

Desde un prisma adjetivo, encontramos la discutible "teoría de la prueba", ${ }^{43}$ consistente en validar la prescripción penal por la cautela del derecho a un juicio con certitud, ya que el transcurso del tiempo eliminaría o mermaría las pruebas del hecho, ${ }^{44}$ lo que, por una parte, dificultaría la tarea del ente persecutor respectivo para acreditarlo, como también, por otra, limitaría las probanzas con las que podrían contar los ciudadanos para defenderse de la imputación criminal. ${ }^{45}$ Esta teoría, sin embargo, ha sido descartada, fundamentalmente porque la dificultad probatoria que ocasiona el tiempo en las evidencias no puede darse por supuesta en todos los casos, como tampoco porque no explica por qué existen distintos plazos

\footnotetext{
${ }^{40}$ Para un detallado análisis de aquellos fundamentos que no han recibido mayor acogida doctrinaria, véase RAGUÉs, cit. (n. 22), pp. 24 y 25, 29 y 30, fundamentalmente aquellos referidos a la "renuncia del Estado al ius puniendi" y sobre la "inactividad de las autoridades y funcionarios encargados de la persecución de delitos".

${ }^{41}$ González TAPia, María José, La prescripción en el Derecho Penal, Dykinson, Madrid, 2003, p. 65.

${ }^{42}$ GonZÁlez, cit. (n. 41), p. 44.

${ }^{43}$ Que para Pessina, Enrico, Elementi di diritto penale, Stamperia Della Regia Universitá, Napoli, 1869, Vol. II, p. 138, era la justificación de la prescripción penal en su antecedente más remoto; el Derecho Griego.

${ }^{44} \mathrm{Al}$ decir de RAgués, cit. (n. 35), p. 12, este fundamento descansa en que el tiempo debilitaría la fiabilidad de la prueba. Así también, Roxin, Claus, Derecho penal, Parte General, Thomson ReutersCivitas, Madrid, 1997, T. I, p. 991.

${ }^{45}$ Parra, cit. (n. 2), p. 209.
} 
prescriptivos asociados a la gravedad de los delitos ${ }^{46}$-pues, siguiendo este fundamento, los plazos debieran ser los mismos para todo ilícito- ${ }^{47} \mathrm{y}$, porque esta teoría no puede asilar un reconocimiento a la prescripción de la pena. ${ }^{48}$ Finalmente, esta teoría no puede hacer frente precisamente a que el tiempo, en la actualidad, puede provocar el efecto inverso en la prueba, esto es, que con los avances de las ciencias o de la tecnología puedan aparecer antecedentes que, lejos de dificultar la existencia del delito, permitan establecerlo. En todo caso, siguiendo los planteamientos de la "Teoría de la prueba", lo cierto es que la dificultad de acreditar el delito o la inocencia del imputado como consecuencia de una presunta incidencia negativa del tiempo en la integridad de las probanzas, no se explica como si de un momento a otro un estrago de proporciones hubiese hecho desaparecer las evidencias del caso, sino que, por el contrario, habrán algunas pruebas que se mantengan, quizás, intactas, otras que según su soporte, tengan menos durabilidad, otras, como testigos, que quizás ya no recuerden con la misma claridad lo sucedido o simplemente no puedan ser habidos para la oportunidad procedimental respectiva; lo que cambiaría, según este postulado, sería el contexto probatorio, el que se vería mermado de manera progresiva hasta volverse insostenible y, por ello, justificaría la concesión de la eximente en un tiempo que el legislador establece como estándar o promedio para asumir que se ha verificado el desgaste demostrativo del hecho.

Igualmente ocurre con el fundamento del "derecho a ser juzgado en un tiempo razonable", cuestión que, en todo caso, solo puede radicarse en los denominados casos de prescripción intra processum, esto es, desde que el procedimiento se ha dirigido ya contra el culpable, donde lo relevante es la evitación del sometimiento de un sujeto al rigor de un enjuiciamiento criminal -afectado, potencialmente, por medidas cautelares u otras limitaciones- por un lapso capaz de lesionar sus derechos. Lo que ocurre es que la proscripción o merma del castigo sería el resultado de la elección entre dos intereses que colisionarían: por una parte, la necesidad de que el derecho imponga las penas de las que son acreedores ciertos sujetos y, por otra, que dicha imposición, una vez iniciada la persecución procedimental, se efectúe dentro de un término razonable, evitándose de este modo que

\footnotetext{
${ }^{46}$ Garraud, R., Traité théorique et practique du Droit Pénal Francaise, Imprenta Sirey, París, 1922, T. II, p. 543.

${ }^{47}$ RAGUÉs, cit. (n. 22), pp. 30-34.

${ }^{48}$ Garraud, cit. (n. 46), p. 543.
} 
el procesamiento constituya un mal que pueda ser incluso mayor que la propia pena. Para ello, sin embargo, se han consignado, en la mayor parte de los ordenamientos, diversas fórmulas que impiden la prolongación del enjuiciamiento, como ocurre con los efectos de la paralización del procedimiento consignados en la parte final del art. 96 CP. ${ }^{49}$ También ha surgido con fuerzas, fundamentalmente en el derecho español, la minorante de "dilaciones indebidas" ${ }^{50}$ que si bien en su radio operativo coincide con el de la llamada prescripción intra processum, difiere de ésta en la exigencia, para su configuración, de que el retardo sea injustificado, excluyendo de su ámbito los retardos imputables al encartado. ${ }^{51}$ Bajo dicha premisa, la afectación del tiempo en los derechos de las personas procesadas no puede ser considerado el fundamento de la prescripción penal, básicamente por dos razones: primero, porque no explica, tampoco, por qué deben existir

\footnotetext{
${ }^{49}$ Fórmulas similares se reconocen en otras latitudes, como el CP español en su art. 132; CP del Perú, art. 83; CP del Uruguay, art. 120. Esta clase de reglas no son, en todo caso, novedosas. Como indica VAn Hoorebere, Emile, Traité des prescriptions en matière pénale, Librairie Vandale, Bruxelles, 1847, p. 5, ya eran conocidas por el Derecho Romano, donde la potestad de acusar pertenecía a todos los ciudadanos y, por lo mismo, el legislador tendía a establecer garantías en favor de los acusados. Allí, como especifica Brun De VILleRET, Louis E., Traité théorique et pratique de la préscription en matière criminelle, A. Durand, Libraire-éditeur, París, 1863, p. 11., una vez que el procedimiento se dirigía contra el culpable, se consagraba una especie de caducidad procesal, que comenzaba a computarse desde la admisión de la acusación. Ya en el s. XIX, el Código Penal Prusiano, para precaver las eventuales paralizaciones eternas de los procedimientos, mandataba que una nueva prescripción comenzara a correr a partir del último acto judicial, si la instrucción no ha conducido a una decisión que adquiera fuerza de cosa juzgada, según se aprecia de su Art. 47, íntegramente transcrito y traducido al castellano en Groizard Y Gómez De La Serna, A., El Código Penal de 1870, concordado y comentado, Imprenta de Timoteo Arnaiz, Burgos, 1872, T. II, p. 597. También existen otros modelos que prescinden de la paralización para que comience a correr nuevamente el término, estableciéndose en su reemplazo que desde que se inicia el proceso comienza a correr, en ese preciso momento, nuevamente la prescripción penal. Así lo reconocen el CP de Alemania, § 78c, n (3); CP de Cuba, art. 64, n 4; CP del Paraguay, art. 104.

${ }^{50}$ Positivamente reconocida por el ordenamiento español desde 2010, por la reforma del Código Penal de 22 de junio de 2010, art. único de la Ley Orgánica 5/2010, en el art. 21.6 CP, aunque en forma previa fue aceptada como atenuante analógica, Como se indica en García SAN MARTín, Jerónimo, Las Medidas Alternativas al cumplimiento de las Penas Privativas de Libertad, Dykinson, Madrid, 2016, p. 90 y cuya razón de ser se halla en el derecho fundamental a un proceso público sin dilaciones indebidas, recogido en el art. 24.2 de la Constitución Española, según sindica DíEz RipolLÉs, José Luis, "Algunas cuestiones sobre la prescripción de la pena", InDret - Revista para el análisis del Derecho, 2008, №2, p. 5, en virtud de la cual se acepta la disminución del castigo punitivo como consecuencia del transcurso del tiempo, sin que se complete la prescripción "plena" del ilícito respectivo, Domínguez IzQuiERDo, "La 'nueva' atenuante de dilación extraordinaria e indebida en la tramitación del procedimiento", Cuadernos de Política Criminal. Segunda Época, 2010, № 102 (dic.), pp. 45-89, p. 47.

${ }^{51}$ Ragués, cit. (n. 35), p. 5. Para un reconocimiento expreso de la incompatibilidad entre las dilaciones indebidas y la prescripción intra processum, véase las siguientes sentencias del Tribunal Supremo español: STS 553/2008, STS 106/2009, STS 318/2013 y STS 4987/2016.
} 
distintos plazos prescriptivos para los diversos delitos, esto es, faltas, simples delitos, crímenes y crímenes con presidio perpetuo, como tampoco los casos de prescripción de la pena y de prescripción extra processum. Sin perjuicio de estas críticas, si estimáramos que este fundamento puede justificar la prescripción penal, lo cierto es que ninguna persona experimenta, de un segundo a otro, la conmoción de sus derechos por estar afectado por un extenso proceso penal, sino que es la prolongación de esta circunstancia la que puede ocasionar una merma en los ciudadanos, gradualmente, fijándose por el legislador, también, un plazo promedio en el que se supone que se torna intolerable la situación, confiriendo, por ello, la exención del castigo.

También se ha sostenido que la prescripción se asila en fines preventivos especiales, esto es, como una contracara a la finalidad de la pena consistente en la evitación de delitos futuros, bien sea a través de la readaptación social del delincuente -prevención especial positiva-, bien mediante el aseguramiento del autor -prevención especial negativa-; en estos supuestos, el tiempo haría desaparecer la necesidad de la pena debido a que la excesiva distancia temporal entre el hecho y su punición terminaría por someter al rigor penal a un sujeto que es una persona absolutamente distinta de aquella que delinquió, de modo que castigarlo en esas circunstancias carecería de sentido. ${ }^{52}$ A este fundamento -como se dijo, contracara de la prevención especial como función de la pena- se le ha denominado, en algunos casos, como "la enmienda del delincuente", donde la necesidad de castigo desaparece con el tiempo porque el delincuente se ha corregido; también, con ciertos matices, en otras oportunidades se le ha llamado "teoría de la expiación moral o indirecta", consistente en que la aflicción que experimenta el delincuente durante el tiempo posterior a su delito resulta ser un equivalente al castigo estatal concretado en la pena. ${ }^{53}$ Este fundamento de la prescripción tuvo reconocimiento parcial en diversas legislaciones, que exigían que para conceder la prescripción la acreditación de un buen comportamiento, ${ }^{54} \mathrm{o}$, como lo hace aún nuestro $\mathrm{CP},{ }^{55}$ que no

\footnotetext{
${ }^{52}$ Serrano González De Murillo, José, "El comienzo del cómputo de la prescripción en los casos de resultados muy posteriores a la conducta típica", Cuadernos de Política Criminal, Segunda época, 2007, $\mathrm{N}^{\circ} 93$ (nov.), pp. 113-142, p. 128.

${ }^{53}$ En contra de este fundamento, GARRAUd, cit. (n. 46), p. 543. A favor, Antón, cit. (n. 37), p. 612 y ss.

${ }^{54}$ Así, el Código Penal Bávaro, en su art. 139, y el CP del Cantón de Friburgo, en su art. 80, ambos íntegramente transcritos en GroIZARD, cit. (n. 49), pp. 595 y 596.

${ }^{55}$ Aunque es replicado en diversos cuerpos punitivos vigentes, como en el art. 121 del CP del Uruguay o el art. 83 del CP del Perú.
} 
se cometiera un nuevo delito durante el curso del término prescriptivo. ${ }^{56}$ Groizard, ${ }^{57}$ refiriéndose a este fundamento, señala que:

“(...) Una nueva caída, un nuevo delito interrumpe también el tiempo de prescripción. Es esto consecuencia natural de los principios ya sentados. El que antes de cumplir una condena reincide, se revela de nuevo contra el derecho que ampara con su sanción penal, da muestras que del hecho de haber escapado al primitivo castigo, lejos de contenerle, le ha alentado á nuevos escesos con la esperanza de la impunidad [sic.]".

Sin perjuicio de lo señalado, en las legislaciones que exigen para la prescripción que no se cometa delito posterior, se presume que el delincuente, con el tiempo, se ha enmendado (exonerándolo, por ello, del castigo), ya que no se requiere probar su efectiva corrección (como sí lo mandataban los primeros Códigos que recogieron esta exigencia), cuestión que hipotéticamente puede favorecer a aquellos criminales que, con el tiempo, perfeccionan su comportamiento delictual para eludir su descubierto. ${ }^{58}$ Sobre estos modelos, cabe efectuar dos prevenciones: la primera, dice relación con la incompatibilidad entre este fundamento y el establecimiento de términos de prescripción diversos en razón de la mayor o menor gravedad de los delitos respectivos. Por ello, en los modelos como el nuestro, donde se establece como evento interruptor del término a la perpetración de un nuevo delito -fundamento preventivo especial-, pero, también consignando plazos de prescripción diversos según la gravedad de los ilícitos - preventivo generales-, pareciera que, al menos en el reconocimiento positivo de la institución convergen fundamentos diversos. Una segunda cuestión que debe señalarse sobre los modelos que estructuran la prescripción penal sobre la base de la prevención especial es la alta dificultad -insuperable- que estas construcciones implican a la hora de hacer frente a los principios rectores de un Derecho Penal asilado

\footnotetext{
${ }^{56} \mathrm{El}$ antecedente más remoto de este tipo de regulación es el Código Penal español de 1822, que así lo consagra en su art. 176, íntegramente transcrito en el Código penal español, decretado por las córtes en 8 de junio, sancionado por el rey, y mandado promulgar, en 9 de julio de 1822, Imprenta Nacional, Madrid, 1822, p. 37.

${ }^{57}$ Groizard, cit. (n. 49), p. 612, refiriéndose al tratamiento que el CP español de 1870 hace en su art. 134 de la prescripción de la pena.

${ }^{58}$ PARra, cit. (n. 2), p. 212.
} 
en un Estado democrático de Derecho. ${ }^{59}$ Ahora bien, en lo que respecta a la media prescripción y a los justificativos radicados en la prevención especial positiva, el cambio en la personalidad del sujeto que delinquió y que no lo volvió a hacer (al menos presuntivamente), evoluciona hasta reinsertarse por completo en la sociedad, de forma progresiva, renunciándose al castigo cuando se alcanza un tiempo que permite asumir, legalmente, que el agente ha enmendado su camino; resulta sumamente complejo de pensar que el delincuente se reinserta de golpe en el segundo exacto en el que alcanza su plazo de prescripción total.

Otro tanto ocurre con los fundamentos de la prescripción penal radicados en la prevención general negativa, respecto a los cuales se ha sostenido que la incidencia del tiempo en el castigo se justificaría porque la punición tardía, al parecer, intimidaría menos a los ciudadanos de abstenerse de ejecutar conductas antijurídicas, pues para conseguir los efectos que la prevención general le atribuye a la pena, se requeriría de la mayor proximidad posible entre el momento de la perpetración del delito y aquel en que se castiga al responsable, ya que con el transcurso del tiempo se atenuaría el recuerdo del delito, disminuyendo la alarma social ocasionada por el comportamiento ilícito. ${ }^{60}$ Sin embargo, esta propuesta ha sido duramente criticada debido a que el castigo tardío de un delito produce exactamente el efecto contrario, esto es, que a pesar de que ha transcurrido una porción considerable de tiempo, el derecho de todos modos reacciona, intimidando a los ciudadanos, por una parte, como también restableciendo la vigencia de las expectativas normativas defraudadas y, con ello, transmitiendo a los ciudadanos el mensaje de que el derecho prevalece, no obstante el tiempo transcurrido - prevención general positiva- ${ }^{61}$ De todos modos, si se aceptase esta posición, resulta a lo menos difícil asumir que la menor intimidación que

\footnotetext{
${ }^{59} \mathrm{Al}$ respecto, véase MuÑoz CONDE, Francisco, La resocialización del delincuente. Análisis y crítica de un mito, en Núñez Barbero, R. (coord.), Estudios Penales, libro homenaje al profesor J. Antón Oneca, Ediciones Universidad de Salamanca, Salamanca, 1982, pp. 390 y ss.

${ }^{60}$ Serrano, cit. (n. 52), p. 126.

${ }^{61}$ Ragués, cit. (n. 22), p. 37. Mir PuIG, Santiago, Derecho Penal, Parte General, Reppertor, Barcelona, $2005,7^{a}$ ed., p. 751 , descarta como fundamento a la prevención general negativa, señalando que materialmente la eximente se justifica en la ausencia de prevención, tanto general como especial, que se devendría con el castigo tardío. Adhiere a la prevención general como fundamento de la prescripción penal, en forma expresa, SERRANO, cit. (n. 52), pp. 126 y 127, quien señala que "Es el propio transcurso del tiempo el que restaura por sí solo la vigencia del ordenamiento jurídico, al ir haciendo desaparecer el carácter perturbador del delito para el orden social, lo que priva de legitimación a una pena ya innecesaria para mantener dicho orden social, puesto que los hechos del pasado han dejado de representar una amenaza para él".
} 
el castigo tardío inferiría en los ciudadanos, o el menor efecto comunicativo del restablecimiento de la vigencia del derecho, opera de un momento a otro, marcado por el día en que se alcanza el plazo total de la eximente.

Mayor éxito ha tenido la fundamentación de la prescripción en la prevención general positiva, lo que encontraría reconocimiento -y compatibilidad-con el establecimiento de plazos de prescripción-menores, mayores, o incluso a fundamentar la imprescriptibilidad de algunos hechossegún la gravedad de los ilícitos.

De allí pareciera arrancar la posición de RAGUÉs, quien plantea que el efecto del tiempo en el hecho criminoso es que éste es percibido como un acontecimiento histórico por la colectividad, perdiendo, con ello, su relevancia social, de modo tal que la potestad punitiva del Estado deja de encontrar justificación y, por tanto, de ser legítima, puesto que la imposición del castigo solo puede extenderse sobre conductas capaces de afectar un interés necesario para la convivencia social, negándose el recurso a la potestad punitiva para tutelar valores de contenido estrictamente moral o ideológico, ${ }^{62}$ como también sobre ilícitos en los que no se vislumbra bien jurídico protegido: ${ }^{63}$ el suceso, con el transcurso del tiempo, habrá perdido toda su capacidad para afectar negativamente al modelo social presente. ${ }^{64}$ En este caso, del mismo modo que en todos los supuestos prescriptivos, es el legislador quien fija un plazo estimativo que, al ser alcanzado, presume que el acontecimiento deja de ser relevante socialmente, eximiéndolo, por ello, de la pena.

Por ello, creemos que, considerando los correctos lineamientos esbozados por RAGUÉs, el fundamento que permite justificar la prescripción penal se halla como contracara a lo que se ha denominado como "retribucionismo expresivo", que sortea con éxito los cuestionamientos

\footnotetext{
${ }^{62}$ Con ello se excluye a las afectaciones insignificantes o de bagatela respecto del bien jurídico tutelado, como se indica en Zaffaroni, Eugenio; Alagia, Alejandro; Slokar, Alejandro, Derecho Penal, Parte General, Editorial Ediar, Buenos Aires, 2002, pp. 128 y 129.

${ }^{63}$ NÁquira, Jaime. "Principios y penas en el Derecho penal chileno", Revista Electrónica de Ciencia Penal y Criminología, 2008, № 10-r2, p. 21.

${ }^{64}$ RAGUÉs, cit. (n. 35), p. 15. Las referencias al modelo español resultan imprescindibles, debido a que, precisamente, dicho ordenamiento no contempla de manera expresa a la media prescripción. Por ello, su reconocimiento, primero doctrinario y luego jurisprudencial, permite justificar lo necesario del instituto, esto es, su carácter imperativo aún a falta de ley que la consigne, por una parte, y, por otra, esta problemática ha devenido en un frondoso y lato desarrollo argumentativo sobre los fundamentos de la misma, que en la actualidad se presentan como un canon ineludible.
} 
que pueden formularse a la prevención general, ${ }^{65} \mathrm{y}$, por otra parte, permite justificar el castigo estatal, al concebir a la pena del modo que sigue:

"(...) [L]a pena, de este modo, resulta justificada como pena retributiva, pero su justificación no es absoluta, en el sentido de las teorías retribucionistas tradicionales, sino relativa, en el sentido en que la pena expresa el reproche por una abuso unilateral de la confianza cuya reciprocidad es indispensable para la estabilidad de las normas de comportamiento cuyo seguimiento posibilita la coexistencia de iguales espacios de libertad. Que la imposición de la pena pueda, de hecho, reforzar las inhibiciones morales de ciudadanos que muestran fidelidad al derecho, sólo puede derivarse de su rol de expresión de juicios reprobatorios por la realización imputable de determinadas formas de comportamiento incorrecto". ${ }^{66}$

Esta posición, por tanto, reconoce la proporcionalidad en el castigo, ${ }^{67}$ abstracta y concreta, ${ }^{68}$ y al ser llevada al ámbito prescriptivo permite, con ello, graduar los plazos de prescripción en razón de la gravedad de los hechos, teniendo como efecto concomitante -pero no como fin- la capacidad comunicativa de la fidelidad del derecho que conlleva la reacción penal. En este sentido, los acontecimientos más graves pasarían a ser un asunto del pasado en mucho más tiempo que las infracciones de entidad menor. Sin perjuicio de lo señalado, es necesario precisar que, para esta posición (aunque bien puede tener un alcance general) en determinadas constelaciones el legislador consideraría a la prescripción con una naturaleza completamente procesal, funcionando como un mecanismo de "selección de casos", prevaleciendo en tales supuestos la búsqueda de la eficacia procesal

${ }^{65}$ Latamente, véase a Schünemann, Bernd, "Sobre la Crítica a la Teoría de la Prevención General Positiva", en Silva Sánchez, J. (ed.), Política Criminal y Nuevo Derecho Penal (Libro Homenaje a Claus Roxin), Editorial Bosch, Barcelona, 1997.

${ }^{66}$ MaÑAlich, Juan Pablo, "Retribucionismo expresivo. Acerca de la función comunicativa de la pena", en Kindhäuser, U.; Mañalich, J. P., Pena y culpabilidad en el Estado democrático de derecho, Editorial B de F, Buenos Aires-Montevideo, 2011, p. 58.

${ }^{67}$ Que, al decir de Mir, cit. (n. 61), pp. 87 y ss., si es “(...) entendida bajo los lineamientos de un Estado de Derecho se transforma en una garantía a favor del individuo consistente en la prohibición de que la medida del castigo trascienda a la gravedad del hecho cometido (.)".

${ }^{68}$ Entendido como se indica en Fuentes CuBILlos, Hernán, "El principio de proporcionalidad en derecho penal: algunas consideraciones acerca de su concretización en el ámbito de la individualización de la pena”, Ius et Praxis, 2008, N 14 (2), pp. 13-42, p. 19, como el “(...) adecuado equilibrio entre la reacción penal y sus presupuestos, tanto en el momento de la individualización legal de la pena (proporcionalidad abstracta) como en el de su aplicación judicial (proporcionalidad concreta)". 
por sobre la necesidad de castigar el delito. Se trata de los términos breves de prescripción -llamadas, en nuestro ordenamiento, como prescripciones de corto tiempo-, donde opera una verdadera anticipación de la concesión de la eximente a un instante anterior a aquel en que el hecho pase real o presuntivamente a ser un acontecimiento del pasado. ${ }^{69}$

Por último, se debe hacer presente que existen autores que enraízan la prescripción penal en un conjunto de fundamentos de la pena, conocidas como "teorías mixtas", que sugieren que la prescripción penal tendría un fundamento múltiple, combinando las diversas teorías señaladas con anterioridad. ${ }^{70}$

En lo que toca a la media prescripción, la afectación que la precedente fundamentación de la eximente tiene en el retribucionismo expresivo permite graduar el efecto del tiempo en el quántum del castigo, reconociendo con su transcurso no solo una solución final, marcada por un régimen que se traduce en todo o nada, sino que aceptando que si transcurre una buena parte de todo (o casi todo) el tiempo de prescripción plena, el castigo deba atenuarse de manera proporcionada y gradual a la cantidad de su capacidad disminuida para afectar negativamente al modelo social presente, ya que el hecho no pasaría de un instante a otro de valer "toda la pena" el día de su perpetración, a valer "nada de pena" el día en que se alcanza el plazo de prescripción plena, pues la disminución en su afectación negativa del modelo social producida por el tiempo se ocasionaría del mismo modo en que se efectúa un conteo decreciente, esto es, que luego de poco tiempo desde su comisión el hecho deja de valer "todo", para pasar a valer un poco menos, y así, de manera sucesiva, hasta llegar a una significación equivalente a nada. Es evidente que resulta complejo, aunque no imposible, establecer cuantitativamente esta disminución por unidad de día o fracción de tiempo transcurrido post hecho hasta completar el término prescriptivo total. Pero ello no obsta a que puedan buscarse fórmulas que permitan establecer, con cierta representatividad, una respuesta morigerada de la reacción penal,

\footnotetext{
${ }^{69}$ Ragués, cit. (n. 35), pp. 15 y 16.

${ }^{70}$ Así, JAKoBs, Günther, Derecho Penal, Parte General, Fundamentos y teoría de la imputación, segunda edición corregida, Trad. Cuello Contreras, J. y Serrano González de M., Marcial Pons, Madrid, 1997, p. 415 y ss. WeLzel, cit. (n. 22), p.357, se inclina por radicar los fundamentos de la prescripción en aspectos procesales, esto es, en la llamada "teoría de la prueba", como también en la ausencia de necesidad de pena. Por su parte, Frister, Helmut, Derecho Penal. Parte general. Trad. Sancinetti, M., Hammurabi, Buenos Aires, 2011, p. 414, reconociendo que ésta es la tendencia dominante, de todos modos, se alinea con los fundamentos adjetivos de la prescripción penal.
} 
como entendemos que lo hace el modelo chileno en el art. $103 \mathrm{CP}$, pues el exceso de punición, si se llega a imponer, carecería de legitimidad: la pena desbordada no encontraría correlato fáctico que la justifique.

\section{Los fundamentos de la media prescripción en Chile}

De los fundamentos latamente referidos en el acápite precedente, aquellos que permitirían justificar la prescripción penal parecieran reconocer, positivamente, a lo menos dos posibilidades: una, en aquellos modelos donde lo relevante, para conceder la eximente, es el hecho delictivo, siendo completamente indiferente el comportamiento del delincuente; y, otra, en aquellos modelos donde el delincuente y su persona, o, más bien, su comportamiento posterior al hecho punible, resultan relevantes para la concesión de la eximente.

La estructuración del sistema chileno, si bien reconocería en su configuración algunos aspectos relativos a la pérdida de capacidad del hecho delictivo para afectar negativamente al modelo social presente, como lo son la graduación de los plazos de prescripción según la gravedad de los delitos, consideró, también, en forma expresa al comportamiento del hechor con posterioridad al delito como un elemento que tiene una incidencia directa en la posibilidad de alcanzar la eximente, pues su recaída delictiva interrumpe el cómputo de una prescripción que corría por un hecho anterior, comenzando a correr nuevamente. Se trata, por tanto, de un modelo mixto, que no se encuentra exento de todos los reproches que puedan formularse a las construcciones que se asilan -aunque sea parcialmente- en la prevención especial.

Sin perjuicio de ello, la premisa que se ha planteado, esto es, que el motivo que sea que justifique la prescripción en un determinado ordenamiento $-\mathrm{y}$ que, en definitiva, dé contenido o explique por qué la necesidad de pena disminuye con el tiempo-, de todos modos implica la disminución paulatina del castigo originario, hasta que llega un momento estimativo en que no se requiere de éste, bien sea como correlato de la nula significación del hecho para afectar el modelo vigente, bien como mecanismo de reinserción social de un sujeto que -al menos presuntivamente- ya no requiere corrección. 


\section{LOS EFECTOS DE LA MEDIA PRESCRIPCIÓN}

\section{Los efectos generales}

La propuesta de este trabajo radica en que los efectos de la regla del art. 103 CP deben armonizarse con la premisa siguiente: en aquellos casos donde falte muy poco tiempo para alcanzar la prescripción total del delito, el rendimiento de las atenuantes en la rebaja debe ser el máximo; en tanto que en aquellos casos donde apenas se hubiere pasado la mitad del tiempo de prescripción total, la rebaja deberá ser menor, aunque, como se dirá, debe efectuarse de todos modos.

En otro orden de ideas, y como antesala, es necesario precisar, primeramente, que la llamada regla de la "media prescripción" no procede cuando, dentro del proceso, se producen dilaciones indebidas. Sin embargo, en nuestra doctrina se ha planteado lo contrario, fundamentalmente por YusEFF, esto es, que por paralizaciones procesales que:

“(...) $[\mathrm{N}] \mathrm{o}$ permitiendo por su duración que sea suficiente para completar el término prescriptivo, habilite al menos para sostener que ha transcurrido la mitad del término y así aplicar esta especie de prescripción incompleta (...)". ${ }^{71}$

Sin embargo, en el modelo chileno ello no es posible de ser aceptado, debido a que el procedimiento, una vez dirigido contra el responsable, provoca la suspensión del término prescriptivo -que afecta tanto el plazo de la "prescripción total" como el de la "media prescripción", que es uno mismo-. A su vez, el mismo art. $96 \mathrm{CP}$ soluciona de forma expresa los casos de paralización del procedimiento, estableciendo que si éste se detiene por más de tres años, la prescripción (total y media) continúa como si no se hubiese "suspendido". ${ }^{72}$ De este modo, entonces, la procedencia de la

\footnotetext{
${ }^{71}$ YusefF, cit. (n. 4), p. 166.

${ }^{72}$ Esta expresión en el texto del art. $96 \mathrm{CP}$, sin embargo, se consigna como "interrumpido", lo que ha sido correctamente sindicado como un error de transcripción del legislador del CP de 1874, pues en la Sesión 140 de la Comisión Redactora, transcrita en RivacoBA, cit. (n. 3), p. 501, la expresión utilizada era "suspendido", no existiendo ningún antecedente que dé cuenta de por qué se produjo el cambio terminológico. Así también lo retrata CuRY, cit. (n. 1), p. 802 y también la Corte Suprema, Rol n 22.660-2014. Sin embargo, esta errónea terminología fue replicada en los artículos que hacen referencia a esta norma en el Código Procesal Penal, v.g., el inciso final del artículo 248 CPP, al señalar los efectos de la decisión de no perseverar del Ministerio Público, indica que "La comunicación de la decisión contemplada en la letra c) precedente dejará sin efecto la formalización de la investigación,
} 
"media prescripción" solo se circunscribe a aquellos casos en que no se esté en presencia de una paralización procedimental, pues en tales casos opera la regla especial de reinicio del cómputo del art. $96 \mathrm{CP}$. El entendimiento que propone YusEFF podría tener sentido en un modelo prescriptivo como el contenido en el CP Español, en donde el direccionamiento del procedimiento contra el culpable constituye una causal de interrupción, en cuya virtud el término prescriptivo que había corrido en favor del culpable se pierde, reanudándose solo cuando el proceso se paralice o termine sin condena, sin señalarse un tiempo máximo de paralización para que se reanude o reinicie el cómputo. En este escenario, como no se indica un plazo de paralización máximo, resulta cuestionable cuánto es el tiempo que debe esperarse para que se produzca la reanudación del cómputo. En el ordenamiento chileno, por el contrario, junto con producirse el efecto de suspenderse el cómputo (no perdiéndose el tiempo de prescripción que el delincuente tenía a su haber), se establece en forma explícita cuánto es el máximo de paralización tolerable ${ }^{73}$-tres años-, de modo que la "media prescripción" es improcedente, pues la prevención sobre la potencial afectación de los derechos del imputado como consecuencia de un sometimiento a un proceso penal por largo tiempo, fue resuelta expresamente a través de la figura de la paralización y la reanudación del cómputo, lo que, además, se condice con los aspectos teóricos del instituto, latamente referidos supra. Así, entonces, la "media prescripción" intra processum, cede ante la especial regulación del art. $96 \mathrm{CP}^{74}$

Ahora bien, en cuanto a los efectos concretos del art. $103 \mathrm{CP}$, en que se plasma la rebaja que debe efectuar el juez ante la concurrencia de la media prescripción, aparecen declarados con nitidez en las Actas de la Comisión

dará lugar a que el juez revoque las medidas cautelares que se hubieren decretado, y la prescripción de la acción penal continuará corriendo como si nunca se hubiere interrumpido"

${ }^{73}$ Como se ha resuelto, esta paralización puede producirse por cualquiera causa, como lo ha resuelto reiteradamente el máximo tribunal nacional, v.g. Corte Suprema, rol n 3.463-2012, Corte Suprema, rol $\mathrm{n}^{\circ} 32.632-2014$, Corte Suprema, rol n 22.660-2014, no obstante que ésta no siempre fue la doctrina dominante, como puede verse en Corte Suprema, rol n 33.626-1956, donde se indicó, en el Considerando $5^{\circ}$, que la paralización, para efectos de servir como requisito de decaimiento de la suspensión, "no puede obedecer a cualquier causa, sino que ella debe tener su origen en una norma legal".

${ }^{74}$ Lo señalado, por supuesto, con la prevención de que el régimen chileno, al considerar el comportamiento del delincuente como un evento que puede afectar la integridad del término prescriptivo que corría por un hecho anterior, reconoce cierta relevancia del tratamiento del "sujeto" por sobre la relevancia del "hecho" y su significación. De seguirse solo esta última premisa como fundamento de la prescripción, la interrupción en los términos del art. 96 CP debiera ser eliminada. 
Redactora del CP, como se lee:

"En cuanto a la prescripción gradual, se creyó que podía concederse al caso de haber transcurrido la mitad o más del tiempo de la prescripción completa, el mismo efecto que si concurrieran dos o más circunstancias atenuantes mui calificadas sin ninguna agravante, es decir, que pueda entónces [sic.] el juez bajar hasta tres grados de la pena designada para el delito, limitándose esta pena para la prescripción que exceda de cinco años". ${ }^{75}$

En este punto, entendemos que la concesión de la rebaja penológica que confiere la "media prescripción" respecto del imputado no funciona con automaticidad. Los mismos fundamentos que se tienen en cuenta para asumir como premisa de este instituto la necesidad de no imponer todo el castigo a quien casi ha completado el término de la prescripción penal que corre a su favor, deben ser asumidos para reconocer que quien acaba de cumplir la mitad del término - haciéndose, desde entonces, acreedor de la "media prescripción" - no debe ser tratado del mismo modo que aquél delincuente que está ad portas de alcanzar la totalidad del plazo prescriptivo, pues en tal caso su necesidad de pena es, de todos modos, mayor que aquella correspondiente a un sujeto que se encuentra, por ejemplo, a un día de alcanzar el término prescriptivo total.

La herramienta de la que se dota a las judicaturas ostenta grados de flexibilidad que, para ser coherentes, deben responder a los mismos criterios de proporcionalidad que se reclaman a la hora de bogar por la legitimidad de la "media prescripción": no debe olvidarse que esta fórmula es un sustituto del complejo modelo que, siguiendo al sr. Fabres, podría predeterminar en cada caso y para cada delito la cantidad de castigo que se impondría al delincuente, como una escala de punición decreciente que se inicia el día del hecho punible, con la totalidad del castigo, y que culmina con el término total de prescripción, con nada de castigo, como tampoco el hecho de que cualquier fundamento teórico que se impute a la prescripción penal, opera de forma paulatina y no de un instante a otro.

La pregunta que de todos modos surge es cómo opera en concreto la norma del art. $103 \mathrm{CP}$ en su reenvío a los arts. 65 y ss. CP. El reenvío contenido en el art. $103 \mathrm{CP}$, imperativamente, sitúa al hecho, dependiendo el tipo de pena que éste tenga, en los arts. 65, 66, 67 o $68 \mathrm{CP}$, premunido

${ }^{75}$ RivacoBA, cit. (n. 3), p.498. 
de a lo menos dos minorantes muy calificadas y ninguna atenuante. Sin embargo, ninguna de estas normas señala en cuántos grados debe rebajarse la pena cuando concurren dos o más atenuantes muy calificadas y ninguna agravante. De allí, entonces, se puede colegir que el reenvío del art. $103 \mathrm{CP}$ a los arts. 65 y ss. CP no se refiere -al menos no de forma explícita- a que con base a estos últimos se precise cuántos grados de pena han de bajarse ante la concurrencia de dos o más minorantes muy calificadas, pues en estas normas, no hay referencia alguna al efecto de esta cantidad de modificatorias de poder extraordinario.

Así, el antiguo art. $65 \mathrm{CP}$, antes de ser modificado por la Ley 17.727 de 1972, solamente reglaba el efecto de una atenuante muy calificada, al tenor que sigue:

"Cuando la lei señala una sola pena indivisible, la aplicará el tribunal sin consideración a las circunstancias agravantes que concurran en el hecho. Pero si hai dos o mas circunstancias atenuantes o una mui calificada i no concurre ninguna agravante, podrá aplicar la pena inmediatamente inferior en grado". ${ }^{76}$

Luego de la vigencia de la Ley 17.727, el efecto de rebajar uno o dos grados pueden ser obtenidos por la concurrencia de dos o más atenuantes ordinarias, eliminándose la referencia a la atenuante muy calificada del texto original del art. $65 \mathrm{CP}$.

La otra referencia a las minorantes muy calificadas la encontramos en el art. 68 bis CP, incorporado por la Ley 17.727, que solo se refiere al efecto de una sola minorante muy calificada:

"art. 68 bis. Sin perjuicio de lo dispuesto en los cuatro artículos anteriores, cuando sólo concurra una atenuante muy calificada el Tribunal podrá imponer la pena inferior en un grado al mínimo de la señalada al delito".

Como se puede apreciar, ninguna de las normas que hacen referencia al efecto de una minorante muy calificada, explicitan el poder atenuatorio de dos o más minorantes muy calificadas, de modo que, al menos de forma expresa, en nuestro $\mathrm{CP}$ no existe una solución clara sobre cuál es el efecto concreto del art. $103 \mathrm{CP}$.

En nuestra doctrina, este problema no ha sido abordado. Solo algunos

${ }^{76}$ Rivacoba, cit. (n. 3), p. 41. 
aspectos se han considerado de manera tangencial a raíz de la discusión sobre las potestades facultativas u obligatorias que tendría el juez de rebajar grado(s) de pena ante la concurrencia de circunstancias atenuantes. En esta línea, YusefF, autor del único estudio especializado que existe respecto a la prescripción penal en Chile, propone solucionar el problema distinguiendo entre la prescripción de la acción penal y de la pena. Respecto a la primera, propone que, obligatoriamente:

“(...) [S]i el hecho tenía agravantes, éstas desaparecen, y como se le debe considerar revestido de dos atenuantes, el juez sólo está obligado a no imponer el grado máximo de la pena asignada por la ley al $\operatorname{delito}(. .). "{ }^{77}$

Por su parte, en lo tocante a rebaja de pena, señala que:

“(...) [P] ara rebajar la pena al grado inmediatamente inferior, en el caso del artículo 65, o de imponer la pena inferior en uno o dos grados al mínimo, en el caso de los artículos 66 y 67, o para rebajar uno, dos o tres grados desde el mínimo, en el caso del artículo 68, el tribunal conserva amplia facultad". ${ }^{78}$

Finalmente, en cuanto a la prescripción de la pena, señala que:

“(...) [S]erá necesaria la dictación de una resolución complementaria de la sentencia primitiva, que impondrá la pena sin considerar las circunstancias agravantes de responsabilidad que puedan haberse tomado en cuenta en la anterior condena, pero sí las atenuantes". ${ }^{79}$

La posición de YusefF, sin embargo, no puede ser aceptada, porque priva al art. $103 \mathrm{CP}$ de todos sus efectos expresamente señalados por el legislador (dos o más atenuantes muy calificadas), relegando la regla a una remisión que solo podría ser validada si el tenor del art. $103 \mathrm{CP}$ no utilizara la expresión "muy calificadas". Además, la postura de YusefF efectúa distinciones entre prescripción de la acción penal y de la pena que el tratamiento del art. $103 \mathrm{CP}$ no contempla en parte alguna, llevando a soluciones absolutamente desproporcionadas con el fin de la norma. En efecto, la propuesta de YusEFF puede llevar a que si un sujeto que cometió

${ }^{77}$ YusefF, cit. (n. 4), p. 164.

${ }^{78}$ YusefF, cit. (n. 4), p. 164.

${ }^{79}$ YusefF, cit. (n. 4), p. 165. 
un delito que tiene asignada pena de crimen -cuyo plazo de prescripción es, en general, de 10 años-, por ejemplo, un robo en lugar habitado, que no ha sido perseguido - prescripción de la acción penal-, donde el delincuente es aprehendido habiendo corrido nueve años y 364 días desde la perpetración del hecho, pueda imponérsele, de todos modos, la pena del marco original de su delito, esto es, de presidio mayor en su grado mínimo, ya que en ella solo se le conferiría al tribunal una mera facultad de rebajar la pena según las reglas de los arts. 65 y ss $\mathrm{CP}$, lo que entra en pugna tanto con el fin del art. $103 \mathrm{CP}$-penar menos a mayor tiempo transcurrido-, pues se permite castigar exactamente lo mismo que si al sujeto del ejemplo lo hubiesen aprehendido en flagrancia el mismo día de la perpetración del delito, como también con el tenor literal de la norma, ya que, en el fondo, al delincuente no se le están confiriendo dos atenuantes muy calificadas en su beneficio, pues podría ser tratado como si no tuviera minorante alguna en su favor.

Por su parte, Mañalich, -también refiriéndose al debate sobre las atribuciones judiciales de rebajar facultativa u obligatoriamente la pena-, ha dicho al respecto que esta regla (la del art. $103 \mathrm{CP}$ ) carecería en la actualidad de un efecto aprovechable, debido a la reforma que en el art. $65 \mathrm{CP}$ introdujo la Ley 17.727 de 1972, en cuya virtud se permite rebajar uno o dos grados de pena solo con la concurrencia de dos o más atenuantes "normales". ${ }^{80}$

$\mathrm{Al}$ respecto, es cierto que el art. $65 \mathrm{CP}$, en su redacción original, se refería al efecto de una minorante muy calificada, como se transcribió supra. También es cierto que la Ley 17.727 de 1972, en el $n^{\circ} 2$ de su art. único dispuso que se suprimiera la expresión "o una muy calificada" del art. $65 \mathrm{CP}$, y reemplazó la palabra "grado" por la frase "uno o dos grados" de la misma norma.

Sin embargo, lo que estos argumentos no ponderan (siendo justos, su objeto es justificar la rebaja obligatoria de pena por parte del juez, mas no profundizar el estudio de los efectos del art. $103 \mathrm{CP}$ ), es que -también a la luz de la historia de la disposición del art. $103 \mathrm{CP}-$, el efecto de la media prescripción y su reenvío a los arts. 65 y ss. CP es uno completamente distinto: el art. $103 \mathrm{CP}$, al conferir al hecho la premunición de dos minorantes muy calificadas y ninguna agravante, permitiría, al menos según se consignó

\footnotetext{
${ }^{80}$ Mañalich RafFo, Juan Pablo, “¿Discrecionalidad judicial en la determinación de la pena en caso de concurrencia de circunstancias atenuantes de la responsabilidad penal?”, en Defensoría Penal Pública (eds.), Informes en derecho $N^{\circ} 7$, Doctrina Procesal Penal, Centro de Documentación de la Defensoría Penal Pública, Santiago de Chile, 2009, p. 35 y ss.
} 
en la historia de la disposición, al juez efectuar una rebaja superior a aquella prevista entonces para una atenuante muy calificada. El efecto del art. 103 $\mathrm{CP}$ es precisamente el de conferir un mínimo de rebaja, de, a lo menos, dos atenuantes muy calificadas. Al respecto, para establecer este mínimo, existen dos posibilidades. Una, consistente en sumar los efectos que a la sazón le asignaba el legislador a una atenuante muy calificada (rebaja de un grado, que es el mismo efecto contenido en el actual art. 68 bis $\mathrm{CP}$ ), permitiéndose, con ello, que la rebaja referida por el art. $103 \mathrm{CP}$ sea de dos o más grados; otra, consistente en reconducir la expresión "muy calificada" del art. 103 $\mathrm{CP}$ al actual art. $68 \mathrm{CP}$, caso en el cual, como bien indica MAÑALICH, el contenido de la expresión "muy calificada" del art. 103 CP carecería de sentido aprovechable.

Una tercera posición sería la siguiente: de conformidad a las reglas vigentes al momento de dictarse el art. $103 \mathrm{CP}$, lo cierto es que dos minorantes muy calificadas debían significar, a lo menos, una rebaja superior a la establecida entonces para una sola atenuante muy calificada (1 grado de pena): esto es, a lo menos dos grados de pena. Ahora bien, ello debe ser complementado con la actual redacción del art. $68 \mathrm{CP}$, donde dos minorantes normales permiten rebajar la pena en 1, 2 o hasta 3 grados, según, como indica la norma, dos criterios: el número y entidad de dichas circunstancias. Pues bien, en cuanto al número, según lo indica el art. $103 \mathrm{CP}$, éste es de a lo menos 2. Pero en cuanto al segundo criterio, lo cierto es que no existe una mayor entidad que la de una atenuante "muy calificada". Por ello, entonces, siguiendo al actual art. $68 \mathrm{CP}$, la rebaja debiese ser la máxima permitida por dicha norma, en atención, como se indicó, al criterio de la "entidad" que ostentan las minorantes muy calificadas. Ese, por tanto, sería el piso mínimo de rebaja previsto por el art. 103 CP. El máximo, por cierto, no está indicado por norma alguna del CP. Al respecto, solo queda la expresión "a lo menos" que consigna el art. 103 CP. La única herramienta que parece capaz de regir la potestad conferida a las judicaturas en torno a determinar cuándo nos encontraremos, en un caso concreto, frente a solo 2 atenuantes muy calificadas (que permita, según esta propuesta, rebajar desde 3 grados de pena), o frente a más de 2 atenuantes muy calificadas, es la proximidad entre el hecho, el juzgamiento del mismo, y el saldo faltante para completar la prescripción total del respectivo ilícito. Desde esta perspectiva, creemos que la norma del art. 103 CP goza de plena vigencia en la actualidad: su objetivo es permitir que el juez, considerando la mayor o menor cercanía con el término prescriptivo total, pueda rebajar en tres o más grados de 
pena al conceder la llamada "media prescripción" en favor del delincuente. Cualquier otro entendimiento implica privar al art. $103 \mathrm{CP}$ de los efectos que allí se consignan para la "media prescripción".

Por lo señalado, no compartimos lo resuelto por la Corte de Apelaciones de Valparaíso al señalar sobre el art. $103 \mathrm{CP}$, que:

“(...) tiene el carácter de orden público y por tanto su aplicación es obligatoria para el sentenciador, en virtud del principio de legalidad que gobierna el derecho penal, por los jueces del fondo están obligados a efectuar y así lo han hecho las juezas a quo. Conforme lo dispuesto tanto en el inciso tercero del artículo 68 del Código Penal, como lo señalado en el artículo 67 inciso $4^{\circ}$ del Código Citado la rebaja en el quantum de la pena corporal en uno, dos o tres grados que corresponda en la especie, queda entregada a la discrecionalidad del juzgador, por lo que en el caso sub-lite, las juzgadoras consideraron que concurrían dos circunstancias atenuantes muy calificadas y ninguna agravante, y estimaron rebajar en un grado al mínimo asignado por la ley al delito de que se trata. Siendo una facultad entregada a los jueces, quienes por mandato del referido artículo 103 del Código Penal, en cuanto al quantum de rebaja, deben aplicar las reglas de los artículos 65, 66, 67 y 68 , del Código citado, las que dan plena libertad para determinar su rebaja en uno, dos o tres grados, para lo cual tendrá en consideración la extensión del daño, al mal causado y la gravedad del delito cometido, por lo que no puede estimarse que se haya cometido una infracción de ley, al haberse rebajado la pena a aplicar en un solo grado(...)". ${ }^{81}$

En este sentido, entendemos que la regla del art. $103 \mathrm{CP}$ entrega a las judicaturas un marco de referencia para aplicar una pena considerablemente menor, según la mayor o menor cercanía con el plazo de prescripción total, que confiere una potestad que no puede ser ejercida con arbitrio, en dos sentidos: uno, en entender que esta rebaja puede o no hacerse, ${ }^{82}$ puesto que el mandato del art. $103 \mathrm{CP}$ es perentorio, en el sentido de la obligatoriedad de

\footnotetext{
${ }^{81}$ Por ello, Corte de Apelaciones de Valparaíso, rol n¹63-2012 (énfasis agregado).

${ }^{82}$ Por ello yerra la Corte de Apelaciones de Santiago, rol n ${ }^{\circ} 778-2009$, que señala que el legislador entrega, en el art. $103 \mathrm{CP}$, “(...) a la discrecionalidad del juzgador la determinación de si procede ejercer o no la atribución concedida para disminuir en uno, dos o tres grados la pena (...)". También se equivoca la Corte Suprema, rol n 2596-2009, al señalar que la "media prescripción” es de “( ...) carácter potestativa, por lo que [los jueces] no se encuentran obligados a disminuir la pena si procede (...)". En el mismo sentido, Corte de Apelaciones de Santiago, rol n 3372-2010.
} 
la rebaja de pena -con independencia de su quántum-que confieren las dos o más atenuantes muy calificadas; $y$, dos, que el fundamento para efectuar la rebaja de pena debe hallarse, como se dijo, en la mayor o menor proximidad del hecho con el término total de prescripción, al momento de direccionarse el procedimiento contra el culpable, lo que exige una motivación en cada caso concreto.

\section{Breve referencia a la media prescripción en los crímenes de lesa humanidad.}

En otro orden de ideas, vinculada con los efectos de la "media prescripción" es la extensa discusión jurisprudencial relativa a la procedencia de ésta en crímenes de lesa humanidad, asentada ya su imprescriptibilidad por las judicaturas nacionales ${ }^{83} \mathrm{y}$, luego, por la Ley 20.357, que tipifica crímenes de lesa humanidad, genocidio y crímenes de guerra. ${ }^{84} \mathrm{El}$ punto radica en la posibilidad de que la norma del art. $103 \mathrm{CP}$ opere con independencia de la prescripción plena, donde el núcleo del debate se ha centrado en determinar si el contenido de esta norma se trata realmente de una especie de prescripción -lo que implica imprimirle las mismas características que a aquélla-, o si más bien se trata de una especial regla de determinación de la pena. La adopción de una u otra posición conlleva la producción de efectos absolutamente desiguales: si la llamada "media prescripción" es entendida como una especie de prescripción, ${ }^{85}$ a ella le serían aplicables, de modo consecuencial, todas las sub instituciones que reglan la prescripción total;

\footnotetext{
${ }^{83}$ Una panorámica sobre la ya superada discusión de prescriptibilidad de los crímenes de lesa humanidad, véase BERNALES, Gerardo, "La imprescriptibilidad de la acción penal en procesos por violaciones a los derechos humanos", Ius et Praxis, 2007, $\mathrm{N}^{\circ} 13,1$, pp. 245-265. Un lato panorama jurisprudencial sobre la media prescripción en esta clase de ilícitos, en NoGUEIRA AlCAlÁ, Humberto, "Informe en derecho sobre precedentes jurisdiccionales en materia de media prescripción”, Ius et Praxis, 2015, N 14, 2, pp. 561-589. Esta problemática, hoy, resulta plenamente atingente tratándose de los nuevos delitos imprescriptibles establecidos por la ley 21.160 .

${ }^{84}$ En su art. 40, la Ley 20.357 establece expresamente que "La acción penal y la pena de los delitos previstos en esta ley no prescriben".

${ }^{85}$ Así, en doctrina, YusefF, cit. (n. 4), p. 161. En nuestra jurisprudencia, véase Corte Suprema, rol 27.178-2014, en fallo del 04 de agosto de 2015, Considerando $27^{\circ}$. En el mismo sentido, Corte Suprema, en autos rol $\mathrm{n}^{\circ} 22.979-2014$, en fallo del 29 de abril de 2015; rol 517-2004, de 17 de noviembre de 2004; rol 17.037-2013, de 8 de octubre de 2014, rol 4240-2014, de 30 de noviembre de 2014; 22.3342014, de 31 de diciembre de 2014; 20.288-2014, en fallo del 13 de abril de 2014, 29.214-2014, de 13 de marzo de 2015 , los cuales, sin embargo, no se pronuncian respecto a la naturaleza de la media prescripción, sino que deciden no aplicarla por no saberse la fecha en que debería haber empezado a
} 
por el contrario, si se estima que la llamada "media prescripción" no es más que una regla especial de determinación de la pena y no una especie de prescripción, ${ }^{86}$ ésta gozaría de autonomía y, además, no le resultaría aplicable el resto del estatuto normativo que el ordenamiento nacional contempla respecto de la prescripción total. ${ }^{87}$ Entendemos que un correcto entendimiento de la "media prescripción" obliga a equiparar su naturaleza con la de la prescripción total: ${ }^{88}$ el fundamento de ambas se encuentra en que la necesidad de la pena disminuye con el tiempo ${ }^{89}$ hasta desaparecer $^{90}$ o, como bien lo retrata Welzel, por la paulatina extinción de la necesidad punitiva en virtud del trascurso del tiempo..$^{91}$ De hecho, ambas son una misma cosa, pero en estadios diversos. Lo que existe es la disminución de la necesidad de castigo que avanza, con el transcurso del tiempo, de forma paulatina, hasta que llega un punto en que lisa y llanamente desaparece. ${ }^{92}$

correr el cómputo del término prescriptivo.

${ }^{86}$ En este sentido, Corte Suprema, rol 8.278-2013, en fallo del 11 de agosto de 2015. En la misma línea, abundantes fallos del mismo tribunal: Corte Suprema, rol 27.960-2014; Corte Suprema, 19 de mayo de 2015. Ésta fue, hasta hace pocos años, la tesis mayoritaria en la jurisprudencia del máximo tribunal, como lo señala FernÁNDEZ NeIRA, Karinna, "La prescripción gradual, aplicada a los delitos de lesa humanidad", tesis para optar al Grado de Magíster, Facultad de Derecho, Universidad de Chile, Santiago, 2010, no publicada, p. 74

${ }^{87}$ Específicamente, si se entiende que la "media prescripción" es una especie de prescripción, el cómputo de ambas debería comenzar a contarse en el mismo momento; la "media prescripción" se vería afectada por la suspensión e interrupción de la prescripción total, a la "media prescripción" se debería aplicar también la norma de la prescripción extraordinaria que duplica los días transcurridos si el delincuente se encuentra fuera del territorio de la república, y no procedería en los delitos imprescriptibles. Si se entiende que la "media prescripción" solo es una especie de regla especial de determinación de la pena, el inicio del cómputo común se mantiene, pero todas las otras consecuencias se verifican de modo autónomo, esto es, que a la "media prescripción" no le afectaría la interrupción ni suspensión verificadas respecto de la prescripción "total", como tampoco la regla de prescripción extraordinaria, y permitiría que en casos de delitos imprescriptibles se pudiera, de todos modos, conceder la "media prescripción" en favor del delincuente.

${ }^{88}$ GuZMÁn, cit. (n. 24), p. 483.

${ }^{89}$ Necesidad de la pena cuya ausencia, como se ha indicado, es presumida por el legislador chileno, PARRA, cit. (n. 2), pp. 213 y 214.

${ }^{90}$ JeSCHECK, cit. (n. 37), p. 822.

${ }^{91}$ Welzel, cit. (n. 22), p. 359. En el mismo sentido se pronuncia AnTón, cit. (n. 37), p. 612.

${ }^{92}$ Por ello no resulta extraño que la propuesta de la "doctrina Dolmestch" al ser llevada a la praxis, fracase rotundamente, pues altera la armonía completa del modelo prescriptivo y sus subinstituciones, en constelaciones tan relevantes como la interrupción de la prescripción, la llamada prescripción extraordinaria y, por supuesto, la concesión de la "media prescripción" a delitos de lesa humanidad. Para profundizar sobre los críticos efectos prácticos de la referida posición jurisprudencial, véase PARRA, cit. (n. 2), pp. 205-208. 
3. La media prescripción frente a nuevas reglas especiales de determinación de la pena.

Por último, en nuestro ordenamiento existen diversas leyes que han modificado las reglas generales de determinación de la pena, ${ }^{93}$ estableciendo un marco rígido consistente en que, salvo presupuestos sumamente excepcionales, las circunstancias modificatorias no inciden en una rebaja o aumento del marco penal señalado por la ley a cada delito. Sobre ellas, en lo relativo a la media prescripción, solo la Ley de Control de Armas consignó expresamente, en su art. 17 b), que excepciona al marco rígido que afecta a ciertos delitos previstos en dicho cuerpo precisamente el art. $103 \mathrm{CP}$, reconociéndole, por tanto, plena vigencia. Sin embargo, ni la Ley de Tránsito ni la Ley 20.931 (llamada comúnmente como Ley de Agenda Corta II), consignaron tal excepción. Por ello y, precisamente basándonos en lo previsto por el aludido art. 17 b) de la Ley de Control de Armas, podría afirmarse, en principio, que estos cuerpos legales proscriben la procedencia del art. $103 \mathrm{CP}$ en los delitos que reglan, ya que no contemplan expresamente (como sí lo hace la Ley de Armas) una excepción al marco rígido que le conceda vigor a la media prescripción. Además, reforzaría esta conclusión el hecho de que estas normas, al excluir la competencia de las reglas de determinación de la pena previstas en los arts. 65 y ss. CP (remplazándolas por el denominado marco rígido), consecuencialmente excluirían también la procedencia del art. $103 \mathrm{CP}$, que se remite precisamente a los arts. $65 \mathrm{y}$ ss. CP. Sin embargo, estimamos que la posición correcta es la contraria, es decir, que la regla de la media prescripción resulta procedente en los delitos con marco rígido de la Ley de Tránsito y de la Ley de Agenda Corta. Como razones, lo primero que cabe anotar es que, al menos formalmente, ni la Ley de Tránsito ni la Ley de Agenda Corta excluyen (pudiendo haberlo hecho)

\footnotetext{
${ }^{93}$ La llamada Ley Emilia, Ley N²0.770, de 16 de septiembre de 2014, "Modifica la ley del tránsito, en lo que se refiere al delito de manejo en estado de ebriedad, causando lesiones graves, gravísimas o, con resultado de muerte"; la Ley 20.813, de 6 de febrero de 2015, "Modifica la Ley 17.798, de control de armas y el Código Procesal Penal"; y la denominada Ley de Agenda Corta II, Ley N 20.931, de 5 de julio de 2016, sobre delitos contra la propiedad cometidos por medios materiales de apropiación, referidas críticamente en PARRA NúÑEZ, Francisco, "La ausencia de apelación para la defensa, ante una solicitud de exclusión de prueba denegada", Revista de la Justicia Penal, 2018, N 12, pp. 69-98, pp. 70 y 71 . Consideraciones sobre el tratamiento de un marco rígido en la determinación e la pena, desde la perspectiva de la Ley de Control de Armas, véase BASCUR, Gonzalo, "Análisis de los principales delitos y su régimen de sanción previsto en la Ley 17.798 sobre Control de Armas", Política criminal, 2017, Vol. 12, № 23 (julio), pp. 590 y 591, con especial relevancia lo señalado en nota al pie $\mathrm{N}^{\circ} 224$.
} 
expresamente la operatividad de la regla del art. 103 CP. Sin embargo, lo que nos parece decisivo para justificar la procedencia del art. $103 \mathrm{CP}$ en esta clase de constelaciones radica en consideraciones sustantivas, esto es, en la afirmación que se ha defendido sobre el carácter dependiente y accesorio de la regla del art. $103 \mathrm{CP}$ respecto de la plena prescripción, en cuya virtud, de haber eximente, hay, consecuencialmente media prescripción, de modo tal que en los delitos reformados en su marco penal, al mantenerse aún respecto de ellos la posibilidad de configurar la prescripción total, ahora sí de modo consecuencial, debe prevalecer también la vigencia de la media prescripción.

Por lo señalado, entonces, y a modo de síntesis, en el modelo chileno la llamada "media prescripción" se encuentra absolutamente vinculada con la prescripción penal, lo que se concreta en que las diversas sub instituciones que la reglan se aplican del mismo modo a la "media prescripción”, siguiendo, como directriz, el axioma de disminución de la necesidad de castigo como fundamento de la renuncia a la punición con el transcurso del tiempo. En síntesis, este lineamiento general se traduce en todos los tópicos que ordenan el régimen prescriptivo nacional: i) la prescripción del delito o de la pena se interrumpe con la comisión de un nuevo delito, comenzando a correr nuevamente desde este acontecimiento; la llamada "media prescripción" se configura solo desde que ha transcurrido a lo menos la mitad del plazo total de prescripción para el ilícito respectivo, interrumpiéndose, también, del mismo modo que la prescripción plena; ii) el direccionamiento del procedimiento contra el delincuente suspende igualmente el curso de la prescripción y de la media prescripción; y iii) la regla de la prescripción extraordinaria, esto es, que computa por "medio" cada día que el sujeto se encuentra ausente del país, es igualmente aplicable para computar la "media prescripción".

\section{CONCLUSIONES}

1.- La configuración del sistema prescriptivo chileno da cuenta del reconocimiento histórico de la media prescripción como una sub institución de la prescripción, que debía operar atenuando el castigo de manera gradual mientras más cerca se encontraba del término de prescripción total. Sin perjuicio de ello, la fórmula ideada por el legislador para reconocer positivamente esta premisa fue la de conferir al hecho la premunición de a lo menos dos minorantes muy calificadas y ninguna agravante. 
2.- Desde una perspectiva dogmática, todos los fundamentos que pretenden explicar la prescripción total de un delito reconocen que la necesidad del castigo disminuye con el curso del tiempo de manera paulatina, día a día, y no de un momento a otro.

3.- En otro orden de ideas, tanto el telos histórico del art. $103 \mathrm{CP}$, como su configuración normativa -relativa a los efectos asociados a la media prescripción-, reconocen la disminución gradual del castigo hasta desaparecer en su totalidad cuando se alcanza el término de prescripción plena. Lo anterior, deviene en que el principio rector del art. $103 \mathrm{CP}$ es atenuar el castigo según la mayor o menor lejanía entre el hecho y el momento de su castigo, en relación también con el tiempo faltante para alcanzar la eximente total.

4.- Consecuencia de lo anterior es que la gama de minorantes que se confieren al hecho con el transcurso del tiempo, según lo previene el art. $103 \mathrm{CP}$, constituye una herramienta sumamente dúctil para adaptarse a los presupuestos fácticos de cada caso, calibrando el rendimiento de éstas según la proximidad del hecho con su castigo.

5.- En cuanto a su radio operativo, el art. $103 \mathrm{CP}$ no procede tratándose de casos de prescripción intra processum, donde es desplazado por la regla de la paralización recogida en el art. $96 \mathrm{CP}$.

6.- El efecto concreto del art. $103 \mathrm{CP}$ requiere analizar tanto las normas vigentes al momento de su promulgación, como las actualmente establecidas en los arts. 65 y ss. CP. En este sentido, al momento de establecerse el art. 103 CP dos minorantes muy calificadas debían significar, a lo menos, una rebaja superior a la establecida entonces para una sola atenuante muy calificada ( 1 grado de pena): es decir, como mínimo dos grados de pena. Según el actual art. $68 \mathrm{CP}, 2$ atenuantes normales permiten rebajar 1, 2 o 3 grados de pena, según dos criterios: el número y la entidad de las mismas. No existe mayor entidad que la de una atenuante muy calificada: por ello, dos minorantes de esta clase no pueden sino permitir acceso al máximo de dicha norma, esto es, 3 grados. Éste es el mínimo de rebaja que debe verificarse por la regla del art. 103 CP. El máximo, no está indicado en parte alguna del CP. Para establecerlo se propone considerar el fundamento de la media prescripción, que, en todo caso, opera paulatinamente hasta alcanzarse la prescripción plena.

7.- Además, se trataría de una sub institución íntimamente ligada a la prescripción penal, siendo una manifestación de la misma en estadios previos y, por lo mismo, si en un caso concreto procede la prescripción total, 
también corresponde reconocer la media prescripción; por el contrario, en aquellos presupuestos de imprescriptibilidad, no es factible que opere la media prescripción. En este sentido, todas las sub instituciones que afectan a la prescripción total (interrupción, suspensión y prescripción extraordinaria) resultan aplicables en idéntica forma a la media prescripción.

\section{BIBLIOGRAFÍA CITADA}

\section{a) Doctrina}

Antón Oneca, José, Derecho Penal, Editorial Akal, Madrid, 1986, $2^{\mathrm{a}}$ ed.

BAscur, Gonzalo, "Análisis de los principales delitos y su régimen de sanción previsto en la Ley 17.798 sobre Control de Armas", Política criminal, 2017, Vol. 12, Nº 23 (julio), pp. 533-609.

Bernales, Gerardo, "La imprescriptibilidad de la acción penal en procesos por violaciones a los derechos humanos", Ius et Praxis, 2007, N 13,1, pp. $245-$ 265.

Brun De Villeret, Louis E., Traité théorique et pratique de la préscription en matière criminelle, A. Durand, Libraire-éditeur, París, 1863.

Bustos Ramírez, Juan, "Imputabilidad y edad penal”, en: Echeburúa, E.; de la Cuesta, J.; Dendaluce, I. (coords.), Criminología y derecho penal al servicio de la persona: libro homenaje al profesor Antonio Beristain, Ed. Instituto Vasco de Criminología, San Sebastián, 1989, pp. 471-482.

CoRtes de España (eds.), Código penal español, decretado por las córtes en 8 de junio, sancionado por el rey, y mandado promulgar, en 9 de julio de 1822, Imprenta Nacional, Madrid, 1822.

Cury Urzúa, Enrique, Derecho Penal, Parte General, Eds. Universidad Católica de Chile, Santiago, 2005, $7^{\mathrm{a}}$ ed., p. 804.

DíEz Ripollés, José Luis, "Algunas cuestiones sobre la prescripción de la pena”, InDret - Revista para el análisis del Derecho, 2008, № 2.

Domínguez IzQuierdo, "La 'nueva' atenuante de dilación extraordinaria e indebida en la tramitación del procedimiento", Cuadernos de Política Criminal. Segunda Época, 2010, º 102 (dic.), pp. 45-89.

Etcheberry, Alfredo, Derecho Penal, Parte General, Editorial Jurídica de Chile, Santiago, 1999, $3^{\text {a }}$ ed. revisada y actualizada, T. II. GArrido MontT, Mario, Derecho penal, parte general, Editorial Jurídica de Chile, Santiago, 2009, 4ª ed. actualizada, p. 398;

Fernández NeIRA, Karinna, "La prescripción gradual, aplicada a los delitos de lesa humanidad", tesis para optar al Grado de Magíster, Facultad de Derecho, Universidad de Chile, Santiago, 2010, no publicada. 
Frister, Helmut, Derecho Penal. Parte general. Trad. Sancinetti, M., Hammurabi, Buenos Aires, 2011.

Fuentes Cubillos, Hernán, "El principio de proporcionalidad en derecho penal: algunas consideraciones acerca de su concretización en el ámbito de la individualización de la pena", Ius et Praxis, 2008, N 14 (2), pp. 13-42.

Garraud, R., Traité théorique et practique du Droit Pénal Francaise, Imprenta Sirey, París, 1922, T. II.

García SAn Martín, Jerónimo, Las Medidas Alternativas al cumplimiento de las Penas Privativas de Libertad, Dykinson, Madrid, 2016.

GonzÁlez TAPIA, María José, La prescripción en el Derecho Penal, Dykinson, Madrid, 2003.

Groizard Y Gómez De La Serna, A., El Código Penal de 1870, concordado y comentado, Imprenta de Timoteo Arnaiz, Burgos, 1872, T. II.

Guzmán Dalbora, José Luis, "Artículos 93 a 105, de la extinción de la responsabilidad penal", en Politoff, S., Ortiz, L.(dirs.), Texto y comentario del Código Penal chileno, Editorial Jurídica de Chile, Santiago, 2002, T. I.

Jakobs, Günther, Derecho Penal, Parte General, Fundamentos y teoría de la imputación, segunda edición corregida, Trad. Cuello Contreras, J. y Serrano González de M., Marcial Pons, Madrid, 1997.

Jescheck, Hans H., Tratado de Derecho Penal, Parte general, Editorial Comares, Granada, 1993, $4^{\mathrm{a}}$ ed.

Lazo, Santiago, Los Códigos Chilenos Anotados: Código Penal, orígenes, concordancias, jurisprudencia, Poblete Cruzat Hnos. editores, Santiago, 1915.

Mañalich Raffo, Juan Pablo, “Discrecionalidad judicial en la determinación de la pena en caso de concurrencia de circunstancias atenuantes de la responsabilidad penal?", en Defensoría Penal Pública (eds.), Informes en derecho $N^{\circ} 7$, Doctrina Procesal Penal, Centro de Documentación de la Defensoría Penal Pública, Santiago de Chile, 2009, p. 35 y ss.

MañAlich RafFo, Juan Pablo, Terror, pena y amnistía: el derecho penal ante el terrorismo de Estado, Flandes Indiano, Santiago, 2010.

MañAlich, Juan Pablo, "Retribucionismo expresivo. Acerca de la función comunicativa de la pena", en Kindhäuser, U.; Mañalich, J. P., Pena y culpabilidad en el Estado democrático de derecho, Editorial B de F, Buenos Aires-Montevideo, 2011.

Mezger, Edmund, Derecho Penal, Parte General, trad. de la $2^{\mathrm{a}}$ ed. alemana por Rodríguez, José, Editorial Revista de Derecho Privado, Madrid, 1957, T. II.

Mir Puig, Santiago, Derecho Penal, Parte General, Reppertor, Barcelona, $2005,7^{\mathrm{a}}$ ed.

Muñoz Conde, Francisco, La resocialización del delincuente. Análisis y crítica de un mito, en Núñez Barbero, R. (coord.), Estudios Penales, libro homenaje al profesor J. Antón Oneca, Ediciones Universidad de Salamanca, Salamanca, 
1982, pp. 390 y ss.

NÁquira, Jaime. "Principios y penas en el Derecho penal chileno", Revista Electrónica de Ciencia Penal y Criminología, 2008, N 10-r2, p. 21.

Nogueira Alcalá, Humberto, "Informe en derecho sobre precedentes jurisdiccionales en materia de media prescripción”, Ius et Praxis, 2015, № 14, 2, pp. 561-589.

PACHECO, El código penal concordado y comentado, Tomo II, Imprenta de D. Santiago Saunaque, Madrid, 1848.

PAcheco, Joaquín, El código penal concordado y comentado, Segunda edición, corregida y aumentada, Imprenta de la viuda de Perinat y Compañía, Madrid, 1856, T. I.

PARRA NúÑEZ, Francisco, "La necesidad de la pena como criterio determinante en la procedencia de la regla del artículo 103 del Código Penal en ilícitos de lesa humanidad: Comentario a la sentencia 34.447-2016 de la Corte Suprema", Revista de Estudios de la Justicia, 2017, º 26, pp. 197-221.

PARRA NúÑEZ, Francisco, "La ausencia de apelación para la defensa, ante una solicitud de exclusión de prueba denegada", Revista de la Justicia Penal, 2018, N 12, pp. 69-98.

PARra NúÑEZ, Francisco, "Prescripción penal y delito permanente", Revista de la Facultad de Derecho (U. de la República, Uruguay), 2019, ํ47, p. 9 y ss., artículo disponible en línea: https://doi.org/10.22187/rfd2019n47a4 (fecha de visita: 12 de septiembre de 2019).

Pessina, Enrico, Elementi di diritto penale, Stamperia Della Regia Universitá, Napoli, 1869, Vol. II.

Politoff, Sergio; Matus, Jean Pierre; Ramírez, María, Lecciones de Derecho Penal chileno, Parte General, Editorial Jurídica de Chile, Santiago, 2004, $2^{\mathrm{a}}$ ed. actualizada.

Prieto, Ana, “Causales de extinción de la responsabilidad criminal; perdón del ofendido, prescripción de la acción penal y de la pena", Memoria de Prueba (pregrado), Facultad de Derecho Universidad de Chile, Editorial Universitaria, Santiago, 1955.

RAGUÉs I VALLÉs, Ramón, La prescripción Penal: fundamento y aplicación, Editorial Atelier, Barcelona, 2004.

RAGUÉs I VALLÉs, Ramón, "La atenuante analógica de cuasiprescripción”, InDret - Revista para el análisis del Derecho, 2017, N³.

Rivacoba Y Rivacoba, Manuel, Código penal de la República de Chile. Actas de las sesiones de la Comisión Redactora del Código Penal Chileno, EDEVAL, Valparaíso, 1974, pp. 290 y 291.

Roxin, Claus, Derecho penal, Parte General, Thomson Reuters-Civitas, Madrid, 1997, T. I.

SchÜnemann, Bernd, "Sobre la Crítica a la Teoría de la Prevención General 
Positiva”, en Silva Sánchez, J. (ed.), Politica Criminal y Nuevo Derecho Penal (Libro Homenaje a Claus Roxin), Editorial Bosch, Barcelona, 1997.

Serrano González De Murillo, José, "El comienzo del cómputo de la prescripción en los casos de resultados muy posteriores a la conducta típica", Cuadernos de Política Criminal, Segunda época, 2007, № 93 (nov.), pp. 113-142.

Stratenwerth, Günter, Derecho Penal, Parte General, Tomo I, El hecho punible, Trad. Canció Meliá, M. y Sancinetti, M., Editorial Aranzandi, Navarra, 2005 .

VAn HoorebeKe, Emile, Traité des prescriptions en matière pénale, Librairie Vandale, Bruxelles, 1847.

Welzel, Hans, Derecho Penal alemán, Trad. de Bustos, Juan y Yáñez, Sergio, Editorial Jurídica de Chile, Santiago, 1976, $2^{\mathrm{a}}$ ed.

Wessels, Johannes, Derecho Penal, Parte General, Trad. de Finzi, Conrado, Depalma, Buenos Aires, 1980, $6^{\text {a }}$ ed. alemana.

Yuseff Sotomayor, Gonzalo, La prescripción penal, Editorial Jurídica de Chile, Santiago, 2009, $3^{\mathrm{a}}$ ed.

Zaffaroni, Eugenio; Alagia, Alejandro; Slokar, Alejandro, Derecho Penal, Parte General, Editorial Ediar, Buenos Aires, 2002.

b) Normas citadas

Código Penal Alemán.

Código Penal Bávaro.

Código Penal de Chile.

Código Procesal Penal de Chile.

Código Penal de Cuba.

Código Penal de España de 1822.

Código Penal de España de 1848.

Código Penal de España de 1850.

Código Penal de España de 1870.

Código Penal de España.

Código Penal Federal de México.

Código Penal del Cantón de Friburgo.

Código Penal del Paraguay.

Código Penal del Perú.

Código Penal del Uruguay.

Ley 17.727, de 1972.

Ley 17.798, de 1972.

Ley 18.290, de 1984.

Ley 20.207, de 2007.

Ley 20.770, de 2014.

Ley 20.813, de 2015. 
Ley 20.931, de 2016.

Ley Orgánica 5/2010, de 2010. (España).

\section{c) Jurisprudencia}

Corte Suprema de Chile, SCS, rol 33.626-1956

Corte Suprema de Chile, 17 de noviembre de 2004, rol 517-2004

Corte Suprema de Chile, 8 de julio de 2010, rol 2.596-2009

Corte Suprema de Chile, 24 de agosto de 2012, rol 3.463-2012

Corte Suprema de Chile, 8 de octubre de 2014, rol 17.037-2013

Corte Suprema de Chile, 11 de agosto de 2015, rol 8.278-2013

Corte Suprema de Chile, 30 de septiembre de 2014, rol 4.240-2014

Corte Suprema de Chile, 13 de abril de 2015, rol 20.288-2014

Corte Suprema de Chile, 31 de diciembre de 2014, rol 22.334- 2014

Corte Suprema de Chile, 22 de enero de 2015, rol 22.660-2014

Corte Suprema de Chile, 29 de abril de 2015, rol 22.979-2014

Corte Suprema de Chile, 4 de agosto de 2015, rol 27.178-2014

Corte Suprema de Chile, 19 de mayo de 2015, rol 27.960-2014

Corte Suprema de Chile, 13 de marzo de 2015, rol 29.214-2014

Corte Suprema de Chile, 29 de enero de 2015, rol 32.632-2014

Corte de Apelaciones de Valparaíso, 8 de marzo de 2012, rol 163-2012

Corte de Apelaciones de Santiago, 6 de noviembre de 2009, rol 778-2009

Corte de Apelaciones de Santiago, 10 de septiembre de 2010, rol 3.372-

Tribunal de Juicio Oral en lo Penal de Talca, 18 de enero de 2013, rol 2142012

Tribunal Supremo Español, 18 de septiembre de 2008, 553/2008

Tribunal Supremo Español, 4 de febrero de 2009, 106/2009

Tribunal Supremo Español, 11 de abril de 2013, 318/2013

Tribunal Supremo Español, 18 de noviembre de 2016, 4987/2016 